\title{
Thermal plasma technology: the prospective future in material processing
}

\author{
Sneha Samal \\ Institute of Physics, University of Rennes 1, France
}

\begin{abstract}
An attempt is made to access the past, present and future research and development in thermal plasma processing of materials. A brief explanation from the basic of thermal plasma understanding towards application of technology in various areas is covered in this article. Such as application of thermal plasma in coating technologies, synthesis of fine powders, waste destruction, spherodization with densification of powders and in slag metallurgy are described from the lab scale basis towards the industrial utilization. Since plasma process is governed by a large number of parameters from input power to furnace configuration. Generation of thermal plasma and various types of plasma reactor is discussed for contribute the significance of output attributes. Finally drawbacks for the growth of thermal plasma technology in commercial aspects are covered up. Keeping in view, the future vision in the area of plasma technology is addressed in this article. Thermal plasma technology and its level of achievements in laboratory and industrial benchmark are covered up in this article. A proposal of future vision in thermal plasma technology draws the attention for commercial benefits and reaches in milestone in industrial area.
\end{abstract}

\section{Key Word}

Thermal plasma technology, research and development, overview, material processing

Email of the corresponding author: samal.sneha-manjaree@ univ.rennes1.fr 


\section{Introduction}

Plasma technology has emerged as a novel technique for the manufacture of newer and better materials in recent years [1]. The high temperature together with the high reactivity due to the presence of free ions and radicals makes the plasma a powerful medium to promote chemical reactions [2]. Plasma can also be very well defined as a physical state of high electrical conductivity with gaseous properties. Plasma can be generated by passing an electric current through a gas. Thermal plasma is initiated when electrons are accelerated between two electrodes in a gaseous environment. The electrons speed towards the anode for collision reaction and excite the atoms or molecules in the gas. The excitation can cause complete or partial ionization. The additional electrons freed by ionization are also accelerated towards the anode and cause more collision and further ionization. As a result highly conductive gas formed and current can pass in the form of an electric spark. Collision between electrons and larger particles become more frequent, these collisions transfer the kinetic energy of the electron and recombination of charged particles raise the temperature of the gas [3]. The ions/neutral atoms in plasma are heated by colliding with electrons. When the gas particles attain the same energy as electrons, the plasma has attended equilibrium for the given electrical energy input. The conductivity of plasma increases with the number of electrons bombarding at the anode. Thereby raising the temperature of the anode and freeing from surface ions that can be easily accelerates towards the cathode [4]. The domain of the plasma is described on the basis of electron density as function of temperature is presented in Fig. 1. The various zone of plasma is portrayed as the function of charge electron density. 
The temperature within the plasma is of the order of $10^{3}$ to $10^{4} \mathrm{~K}$ depends on the degree of ionization. The electrons in the plasma will generally be at $10,000{ }^{\circ} \mathrm{K}$. Due to significant degree of ionization, plasma conducts electricity with a conductivity closed to that of a molten salt state [5]. In comparison to ordinary gas the free electric charges in plasma give rise to high electrical conductivity. Since gases at room temperature are excellent insulators a sufficient number of charge carriers have to be generated to make the gas electrically conducting.

The plasma technology for industrial processes essentially uses two different modes such as "thermal plasma" or "hot plasma" and "non-equilibrium" or "cold plasma". Thermal plasma, is produced at high pressure $(>10 \mathrm{kPa})$ by means of direct $(\mathrm{DC})$ or alternating current $(\mathrm{AC})$ or radio frequency $(\mathrm{RF})$ or microwave sources with temperatures around 2,000-20,000 K. Non equilibrium plasmas are low pressure plasmas characterized by high electron temperatures and low ion and neutral temperatures [6]. The schematic diagram of hot plasma and cold plasma is described in Fig. 2. The thermal or equilibrium plasmas are characterized by high energy density and equality in between the temperature of heavy particles $\left(T_{h}\right)$ and electrons $\left(T_{e}\right)$, such as $\left(T_{h}=T_{e}\right)$. Typical examples of thermal plasma are DC transferred arcs, plasma torches and RF inductively coupled discharges. The second type of plasma is cold plasma characterized by low energy density and large difference between electron and heavy particle temperature $\left(T_{e} \geq T_{h}\right)$ [8-9]. Typical examples are in glow discharges, low pressure RF discharges and corona discharges. The use of non equilibrium plasmas in lighting, surface cleaning, etching, film deposition, etc has been well established. The use of thermal plasma in the area of cutting, welding and spraying has well known over the four decades. Thermal plasma generation devices, 
known as torches, produce plasmas with electron and ion temperatures of the order of 1-2 $\mathrm{eV}$ and with very low gas ionization. A plasma beam more commonly know as plasma jet is produced from a plasma torch (also known as plasmatron). The plasma jet produces an effluent over a wide range of composition and operating conditions over the controlling parameters that can be easily controlled. The high temperatures, enthalpies and heat fluxes obtained from the plasma jet are far higher and widespread application in material processing. DC and AC torches can be divided into transferred and non-transferred arc. However cold or non equilibrium plasma is produced under vacuum conditions using low power RF or microwave or DC sources [7]. The various categories of the plasma system are presented as flow chart in Fig. 3.

Thermal plasma technology has passed through a gradual transition stage from primarily space related activities in the sixties to a more and more materials oriented focus in the eighties and nineties. Space related needs provided a strong impetus for basic thermal plasma research and development [8]. The more conventional applications of thermal plasma technology cover nowadays on wide spectrum of applications on materials processing. Theses application of thermal plasma technology may be classified as thermal plasma in cleaning technology such as waste destruction, in particular toxic waste materials [9], coating techniques such as including plasma spraying, plasma chemical vapor deposition (CVD), thermal plasma in metallurgy [10], thermal plasma synthesis of fine/ nano powders [11] and thermal plasma in extractive metallurgy, including recovery of metal values in industrial application [12]. As conventional plasma torches employ argon and nitrogen as plasma gases. With the additives like hydrogen and hydrocarbons or oxygen, the plasma gas enters the reaction scheme, with the ions and 
excited species. The versatility of the thermal plasma techniques and its benefits favor the adoption of technique by designing dedicated systems to meet specific requirements in plasma processing system [13]. Thermal plasma technology is emerging as a new and the most efficient technique in the field of material science and materials processing [14]. Although thermal plasma has emerged from last century as one of the alternative technique for materials processing and synthesis still a gap is observed in making the process commercially effective in industrial application. More electrical energy consumption is the hurdle for making the process economical effective and commercial benefit.

So here, in this overview, an attempt is made to assess the present situation in these fields, basically in materials processing within the reach of industrial application in commercial way with economical benefit. The main aim is to investigate the application of thermal plasma in the materials processing areas that will bring the prospective future in industrial application on commercial way. The article will provide an overall platform for the researchers and industrialist on the status of thermal plasma technique and its present status and utilization from laboratory scale to industrial market.

\section{Application/ Opportunities}

Thermal plasma technology is a tool for materials processing that has been used for over 45 years, since the development of the initial plasma arc gas heaters. However, the thermal plasma processes slowly fulfills the development of applications and have not reached the desired standard yet [15]. One of the potential applications of thermal plasma is in the areas of extractive metallurgy [16] for recovery of metal values from slag and production of nitride areas such as $\mathrm{AlN}, \mathrm{SiC}, \mathrm{Si}_{3} \mathrm{~N}_{4}$ etc. The smelting part covers [17-20] 
in process of metal alloying (Pt-based super-alloys and Ni-based super-alloys). Also in the areas of thermal plasma processing of metal nano powder formation, refractory and refining [21] and destruction of waste materials [22]. The deposition areas covers [23] coatings for corrosion and wear protection (with red mud as coating on metal to avoid corrosion), thin film deposition, composite material, metal/Ceramic matrix materials and superconductive oxide processing. Fig. 4 portrays the application of plasma processing in various areas from low cost technology towards high cost manufacturing products.

The opportunities of thermal plasma technology are widespread; however, critical research and development needs must be addressed to enable more extensive use of this technology. Thermal plasma processing is still in the laboratory or pilot-plant stage [24-25]. The potential of many thermal plasma processes seems to emerging as new technologies; need to have a strong impact on the economy. Fig. 5 displays the plasma manufacturing process in various categories.

\section{Thermal Plasma Characteristics}

Thermal plasma is described as the bulk of the plasma approaches a state of local thermodynamic equilibrium (LTE). LTE is generally explained as the thermodynamic state approached by an optically thin (the plasma doesn't absorb any of its own radiation), collision dominated plasma in regions with spatial variations are small enough to allow the moving plasma species to adjust continually to their environment. Such plasmas are used in large-scale pyrometallurgical processes that can be generated exclusively from a high density arc discharge configuration. This arc or thermal plasma is always derived from a cathode and terminates at an anode. The specific shape and composition of these electrodes are varied. Electrodes shaped as rods, bottons, tubes or 
rings are common. Rod and button electrodes are usually made of throiated tungsten (2 to 3 per cent $\mathrm{ThO}_{2}$ ) or graphite. This has led to the generally accepted categorized of all plasma devices into either transferred arc [26] or non-transferred arc [27] systems. The power generated by a given device is dependent on its operating current and voltage and is required to meet the energy needs of the process.

The principal advantages of thermal plasmas for materials processing are the freedom in choice of medium at high energy density (high specific heat) with variable electrical conductivity. The plasma generators have essentially two functions the transformation of electrical energy into thermal or plasma energy, and the transfer of the plasma energy to the material. In order to utilize the advantages of thermal plasmas, the energy transfer should take place at temperature levels above $3000 \mathrm{~K}$ [28]. The various zones of temperature distribution in thermal plasma arc are shown in Fig. 6. At these temperatures, the energy transfer from the plasma to a solid or a cold reactant is associated with strong gradients of temperature, density and composition.

Plasma is generated by a current flowing in a partially or fully ionized gas, dissipating sufficient energy to keep the gas ionized and conducting. Although electrons oscillate the energy enhancement from the applied electric field, the high number of collisions between electrons and other components of the plasma assure equilibrium distribution of the internal energy. The requirement for high collision frequencies sets at lower limit of the thermal plasma in the range of between 0.01 and 0.1 atmospheric pressure. Since in thermal plasma the molecular components are mostly dissociated and atomic species are partially ionized, the energy transport occurs not only by transfer of kinetic energy as in ordinary gases, but includes transfer of the heat of dissociation and 
ionization [29]. Electrons transport heat more efficiently by thermal conductivity that considerably higher than those of gases, and vary with temperature.

There are two types of discharges commonly used for the generation of thermal plasmas, the electric arc (DC or AC) [ 30] and the high frequency and radio frequency (HF or RF) induction discharge. In the arc discharge, the plasma generating current flows from one electrode to the other through the plasma [31]. The size of the plasma column is determined by the balance of electric power dissipation with heat loss by conduction, radiation and convection. Fig. 7 displays the schematic diagram of both non transferred and transferred arc reactors. Energy densities increase for the specific gases (plasmagen) the order of argon, nitrogen, helium, hydrogen [32].

Two principal uses of plasmas in materials processing are the bulk heating/ reacting of reactants and the energy transfer to surfaces. The principles of discharge of plasma in materials processing is described as below such as

The raw material is passed directly through the discharge; in this case the material is exposed to the highest heating rates, and the power dissipation will adjust to the heating requirements and will only be limited by the plasma system design.

The plasma is extracted from the discharge region by a superimposed flow, and this plasma jet is used to treat the materials; mixing of the plasma jet with the material or with a cold environment that limit the amount of energy available for the treatment. Both, arc discharges and HF discharges can be used for these arrangements. 
For the treatment of a metallic surface, an arc discharge can be transferred to the surface making it one of the electrodes; the highest surface heating rates and most efficient energy transfers are obtained in this way.

Plasma generators are classified according to the generation method as arc discharge (DC or AC plasma torch) or HF induction generators. The arc discharge requires emission of electrons from the cathode, and there are two basic mechanisms such as

Thermo ionic emission from a surface heated to a temperature allowing the escape of sufficiently large numbers of electrons from the conduction band; typically temperatures above $3000 \mathrm{~K}$ are needed for this emission mechanism, and refractory metals like $\mathrm{W}$ are used to avoid bulk melting; addition of a low work function material such as $\mathrm{ThO}_{2}$ or $\mathrm{La}_{2} \mathrm{O}_{3}$ to the $\mathrm{W}$ will increase the number of electrons emitted at a given temperature.

Field emission of electrons due to high electric fields in front of the surface; this emission mechanism rarely provides a sufficient number of electrons for arc plasmas, but a combination of field with thermo-ionic emission (TF emission), or with an emission mechanism that creates evaporation sites microscopically provide a partially ionized metal vapor, is the dominant provider of electrons with "cold cathodes" such as water cooled copper [29].

Thermal plasma synthesis offers a versatile, cost effective technology for the industrial scale production of many advanced materials for demanding applications in high technologies industries. The need for materials with improved physical and 
mechanical properties for demanding applications is becoming increasingly apparent in such high technical industries as aerospace, chemicals, electronics, semiconductors, transportations and nuclear power [33].

Plasma processing has inherent advantages in the production of advanced materials such in the wide field of nano materials. At high temperatures chemically reactive species formed in the plasma through vapour phase reaction may accelerate chemical reactions for production of nano particles. Residence time in the hightemperature zone is short and controllable. The ability to quench rapidly from very high temperatures produces spherical and ultrafine particles. By suitable choice of feed gases, reactions can take place in an inert atmosphere, or a suitable oxidizing, reducing or other reactive environment. Starting materials (precursors) can be fed to the plasma reactors in the powdered form. Generally, reactants can be chosen to avoid the production of corrosive or toxic products e.g., metals can be fed as oxides rather than chlorides [34].

A major advantage of plasma processing is that, as a consequence of the rapid quenching that can be achieved, materials can be produced in metastable stage under ambient conditions means the materials that face difficult in fabrication or synthesis under more static conditions. The economics related to thermal plasma product of highvalue materials on the basis of purity and particle size distribution is more attractive. Thermal plasma processing is highly needed due to the following reasons [35]

- High surface area and high temperature strength

- Reduction reactions

- Highly endothermic reactions 
- Volume of reactive zone (flame) expanded increasing the throughout using suitable reactor.

Presence of ionic and excited species and high temperature increases the reaction kinetics.

- $\quad$ Processing time reduced considerably

- Flexibility in reactive gases such as $\mathrm{Ar}, \mathrm{N}_{2}, \mathrm{O}_{2}$ etc.

- Ore fines can be directly charged.

- The high temperature and high energy density in the thermal plasma renders relatively high output.

- The plasma heating has wide flexibility on choice of precursors.

- High energy density $\left(10^{5}-10^{7} \mathrm{w} / \mathrm{cm}^{2}\right)$ and high gas/ ion temperature $(\sim 15,000 \mathrm{~K})$

- $\quad$ Electric arc (plasmagen gas - Argon) (IP- $15.75 \mathrm{ev})$

- Heat produced due to recombination and collision

- Temperature: $10^{3}$ to $10^{4} \mathrm{~K}$

- Charged particle's concentration: $10^{16}$ to $10^{17} / \mathrm{c} . \mathrm{c}$

Thermal plasma is used in the production of metals from ores are generally referred to as "plasma metallurgy" for direct reduction of oxide ores, carbon reduction smelting of metal oxides, decomposition of ores and reduction of chlorides etc.

The use of thermal plasma in extractive metallurgy [36] has the following advantages

1. It produces a continuously stable ultra high temperature and has a high rate of heat transfer into the object to be heated, making it possible to achieve a reaction that requires an ultra high temperature. In addition, the rate of reaction increases exponentially as the temperature rises. 
2. It can be used with any kind of plasma generating gases according to purpose, including inert gases, oxidizing gases and reducing gases.

3. It is capable of continuous treatment of pulverized materials; it is capable of reduction and thermal decomposition of powdered ores by feeding them into high temperature plasma.

4. Evaporation loss is small as melting is carried out under ordinary pressure.

5. Melting operation, such as output control is easy.

On the other hand, the obstacle in thermal plasma is consumption of large quantities of electric power and gas such as argon. However many attempts were carried out to reduce the energy consumption of thermal plasma process as follows

6. Refining effect can be expected as melting is done in inert or reducing gas atmosphere.

7. Molten slag/metal reaction can be used for refining by an additional flux.

DC transferred-arc plasma technology is widely preferred for metallurgical processing for the following reasons [37].

The electrical supply characteristics and geometrical arrangement of the transferred-arc furnace are similar to those of conventional submerged arc furnaces, and the change to DC operation is relatively straightforward.

- Scale up to industrial operation, when a graphite electrode is used, is now feasible.

- The use of an open bath of liquid slag and metal (the anode) permits greater control of the process metallurgy than with a choke-fed furnace (include the tap hole in plasma reactor).

- Transferred-arc devices have low cooling-water losses (usually less than 10 per cent) 
The most important feature of DC operation is the ability to sustain longer, more stable arcs than AC operation, with independent current and voltage control. As a result, a significant reduction of electrode consumption, electrical disturbances, and noise can be obtained. However, the thermal efficiency of the plasma-arc furnace is lower than that of a sub-merged arc furnace. Three factors are responsible as follows

i) More energy is lost, by radiation from the open arc and molten bath, to the walls and roof of the furnace.

ii) Some vaporized material is lost to the off gas stream from the arc attachment zone.

iii) Little of the sensible energy of the gases evolved is utilized in preheating the feed material.

The open bath system provides opportunities for excellent process and product control, but is limited by the loss of volatile materials to the off gases and by the relatively high losses of power to the roof (50 to $\left.150 \mathrm{~kW} / \mathrm{m}^{2}\right)$. High throughput rates are therefore necessary to offset the various mechanisms of energy loss. Industrial scale implementation of DC plasma arc technology followed rapidly on the demonstration scale test work carried out at Mintek (company at Johannesburg, South Africa). The first two applications were for ferrochromium smelting and remelting of metal fines, and ferromanganese fines melting [38].

In a comparison between DC, AC arc, and DC plasma gun arc, the graphite cathode DC arc provides the most efficient energy transfer, with the largest portion of the arc power being transferred directly to the melt. The DC arc, with stable unidirectional convention, is superior to the $\mathrm{AC}$ arc in transferring its energy directly to the anode in a metallurgical process. The consumable graphite electrode is able to operate without water 
cooling at far higher current and power levels than a plasma torch with water cooled metal electrodes. Thus the combination of DC power and graphite electrode provides greater and more flexible opportunities for commercial metallurgical process. The disadvantageous of $\mathrm{DC}$, compared to $\mathrm{AC}$, involve the necessity for an electrical connection to the liquid metal anode and the extra cost and space required for rectification. The major factor affecting electrode erosion is the arc current. Consequently, for a particular power requirement, any decrease in the current arising from an increase in the voltage implies a decrease in electrode consumption. At high currents, the electrode erosion rate is lower for graphite than (the major competitor in transferred-arc devices), thoriated tungsten. However, the improvements in arc stability have usually been accompanied by additional costs such as inert gas injection, water cooling of the plasma device, or rectification of the power supply. Hollow graphite electrodes are usually used as cathodes, but water cooled electrodes have also been used. Graphite electrodes are preferred for most purposes as they impose no limits on current, are simpler and introduce no source of water into the furnace [39].

\section{Thermal Plasma Generators}

Thermal plasma jets are generated in direct and alternating current arc discharges. Main requirements for industrial plasma generators are the power efficiency and continuous service life. High frequency (HF) (0.5-5 MHz) plasmatrons for power up to $1 \mathrm{MW}$ have efficiency $50-75 \%$. In arc-plasmatrons the discharge is burning between rod or tubular electrodes and is stabilized by the flow of a plasma forming gas. The arc discharge is fed by direct or alternating current from $100 \mathrm{~A}$ up to $10 \mathrm{kA}$ on voltage level from 50 up to 1000V. Arc plasma generators operating at high (up to 100 bars) and low (up to 10-4 bar) 
pressure, with a hollow cathode as well as pulse arc plasmatrons. In high frequency plasmatrons, HF plasma jets are not contaminated by products of electrode erosion and are essentially pure. HF induction plasmatrons on power level $0.5-1 \mathrm{MW}$ with frequency about $0.5 \mathrm{MHz}$ may operate both with quartz and metallic discharge chambers on various plasma forming gasses including oxygen, chlorine and vapors of reactive substances.

The plasma arc generators are divided into non-transferred arc plasma torch and transferred arc plasma torch. The heating efficiency ranges between $50 \%$ and 90\% and increases with the increase of the gaseous flow. Use of non reactive plasmas, for instance argon, maximizes the electrode life, but decreases the thermal efficiency. It has been mainly used for the pyrolysis of liquid or in waste materials destruction and nano powders formation [40]. The interaction of the corrosive elements leads to high erosion rates requiring frequent change of the electrodes. Therefore, the reactants are more frequently injected into the plasma jet downstream of the electrodes.

\section{1. $\quad$ DC Non-Transferred Arcs}

In the non-transferred arc torch the two electrodes do not participate in the process and have the sole function of plasma generation. It produce a high temperature plasma jet that allows the material to be processed can be injected for in-flight melting operation. The plasma jets have maximum temperature in the order of $12,000 \mathrm{~K}$ and velocities as high as $600 \mathrm{~m} / \mathrm{s}$. The couple of electrodes could have different geometry; a cylindrical bar (cathode) and a hollow cylinder (anode) or two coaxial cylinders that could operate with opposite polarities. The electrodes are generally water cooled and many designs use magnetic axial fields generated by a direct current passing through a coil that surrounds the electrodes. Non transferred arc torches are available with levels of 
power between $1 \mathrm{~kW}$ to $6 \mathrm{MW}$. Fig. 8 shows the schematic diagram of the non transferred arc reactors use in thermal plasma synthesis of nano particles [41].

\subsection{Transferred Arcs}

In the transferred arc reactors, one of the electrodes (anode) is external, so that the arc has transferred to the external anode constituted by an electrically conductive material. This allows the use of extremely elevated thermal fluxes for the substance treatments (metal melting, slag vitrification). In the transferred arc, the physical separation between the cathode and the anode is relatively large. The plasma arc length can be from few centimeters to almost a meter in high power industrial furnaces. Such plasma generating devices can be operated with a minimal plasma gas flow rate for a given power level compared to DC non transferred arc torches.

The substance is placed in an electrically grounded metallic vessel acting as anode. The arc initiates between the cathode and the container carrying the substance to locally elevated temperatures; the substances are liquefied, subsequently vitrified reaching the complete inertisation. The cathode can be constructed by a water cooled metal or by consumable through sublimation conductor material. The consumable cathode generally graphite has the advantages that some time it adds as reductant in slag metal extraction. The disadvantage is that it contaminates the products with carbon and requires a more frequent substitution. The non consumable electrodes have generally a longer life but need more attention to prevent erosion from causing fluid leaks inside torch. The transferred arc reactors had been initially developed for metallurgical processes with power up to many MW and therefore, transferring this technology to the toxic waste destruction has been very rapid and easy. These reactors can have heating efficiencies 
higher than $90 \%$ with limited requirements of gaseous flow for the plasma generation. Fig. 9 display the schematic diagram of static bed transferred arc reactor [42].

\subsection{The Extended Arc}

The electrical characteristics of the conventional carbon arc can be improved significantly by the introduction of an appropriate arc stabilizer into the arc zone. This modified or extended arc that can be created between the graphite electrodes is much more stable than the conventional carbon arc. Thus, this technique provides an alternative to both the conventional plasma furnace that the plasma is generated with in a non consumable electrode or a plasma gun, and the usual carbon arc furnace. Usually argon is introduced into the arc zone through an axial hole of one of the electrodes. Once the electrodes are hot, the gas ionizes quite readily. It is then possible to extend the arc length considerably. At the same time the noise level is reduced dramatically. Fig. 10 shows the transferred arc reactor in extended arc reactor. The extended arc also can be applied to moving bed plasma reactor transferred arc reactor (Fig. 11) [43].

\subsection{RF Inductively Coupled Discharges}

RF induction plasma torches are coupled with energy to plasma with accomplished through the electromagnetic field of the induction coil. The plasma gas doesnot come in contact with electrodes eliminating the possible contamination. The plasma torches can operate with wide range of gases including inert, reducing, oxidizing and other atmospheres. The input power ranges from $30 \mathrm{~kW}$ to $1 \mathrm{MW}$ industrial level. Fig. 12 shows the schematic diagram of RF inductively coupled discharge [44]. The plasma is considerable in larger volume than corresponding dc plasma jets at same power level.

\section{Advantages of Plasma Processing and Its Industrial Applications}


Some unique advantages of plasma-arc furnace technology have been utilized for developing industrial applications of thermal plasma stated below

\subsection{Fine particle feed capability}

The direct use of fine feed materials is possible, without the need for costly agglomeration. Plasma systems can operate with a wide range of gas flow rates allowing fine particles to be introduced into a flowing stream. Under low gas flow conditions, fine particles can be bulk charged into a reactor with minimal entrainment and carry over in the off gas. Particles can be introduced through a hollow electrode for maximum exposure to the high temperature arc environment.

\subsection{Independent Energy Source}

The feed rate and power can be controlled independently. The electrical conductivity of the materials does not limit input power. The power input to the furnace is largely unconstrained by the resistivity of the materials smelted or remelted. This allows greater freedom of choice with respect to charge composition, without having to consider the electrical characteristics of the charge.

\subsection{Gas environmental control}

Energy can be provided to a system with any desired oxygen potential (i.e. oxidizing, reducing, or inert gas conditions), independent of the temperature. This is a distinct advantage over combustion systems that the available energy flux and the oxygen potential are not independent of temperature and reactions are highly endothermic or require strongly reducing conditions.

\subsection{High Temperature}


The usual gas temperature range of 3000 to $6000{ }^{\circ} \mathrm{C}$ (even up to $10000{ }^{\circ} \mathrm{C}$ ) and the gas enthalpies for plasma systems can be significantly higher than combustion energy source.

\subsection{High energy fluxes}

High energy fluxes are a result of the higher temperature with high jet velocities and high thermal conductivities of plasma gases that permit the design of the reactors with high reaction volume densities. For transferred arcs, there is an additional energy flux from the electron transfer at the anode arc root-attachment area. High energy flux allows high smelting capacity with smaller furnace dimensions.

\subsection{High throughput}

There is considerable scope for the achievement of high throughputs in open bath processes, because of the higher reaction rates attained by the use of finer feed particles.

\subsection{Gas flow rate control}

The gas mass flow rate and temperature can be controlled independently of the energy input, by proper selection of the plasma system. In combustion systems, the gas flow rate, temperature, and energy input are independent.

\subsection{Rapid response}

The furnace can respond to changes in a relatively short period.

\subsection{Low electrode consumption}

The pre-baked graphite electrodes used in DC transferred arc furnaces are consumed more slowly than the self baking Soderberg electrodes usually used in AC furnaces, resulting in a higher degree of purity of the melt. Electrode consumption is lower, but the electrodes are usually of higher quality and are therefore more expensive. 
The lower electrode consumption is due partly to the lower electrode surface area and partly to the lower tip erosion encountered.

\subsection{Control of refractory consumption}

Maximum throughput and furnace efficiency would be attained if a liquid slag layer were maintained right up to the side walls. This would be expected to result in high refractory costs due to slag erosion of the side wall refractories. A controlled 'freeze lining' of maximum thickness would be the ideal solution to for the high degree of control furnace.

\subsection{Low noise level}

Electrical and acoustic noise levels are reduced significantly in thermal plasma processes.

\section{Barriers for commercialization}

Thermal plasma processing has found limited application due to

- high utilization of electric power

- Equipment performance/life

- Lack of process understanding

- Lack of process control

- Low process yields

These factors are barrier from historically in the use of thermal plasma processing as commercially viable methods in materials processing techniques. In the developed countries like India, where power of electricity is costlier makes an obstacle in this process. The lack of process understanding as well as on consideration of process variables is the largest contributors to these barriers. The developed process understanding would be used to develop improved equipment and processes. The 
processes behind the heat transfer and reaction kinetics to surrounding particles need to be improved as well as understandable. These understanding will help to increase production rates and yield of production in terms of melting and reaction which is too low for the large scale productions. This will help to remove the barrier which develop at lab scale basis and increase the commercialization in large scale basis.

6.

Application of Thermal Plasma

\subsection{Thermal Plasma treatment of waste materials}

Waste treatment is one of the application areas that maintain the promises for thermal plasma utilization. Research activities in these areas are aimed at either the reclamation of waste material in order to recover higher added value products or the rendering of waste to inert form or the destruction of toxic waste. The use of thermal plasma technology provides a controlled heat source that is used to melt the feed stock (in the form of drums of mixed waste) and to maintain a high temperature molten bath. The high temperatures enable the oxidation of organic materials and their separation from soils etc leading to the destruction of contaminants, containment of hazardous materials and potential recovery of useful byproducts (metals, chemicals etc.). One novel extension of the thermal plasma approach to the problem of contaminated soils is to process the soils in situ providing good containment of the hazards with minimal off gas and particulate problems while eliminating most of the materials handing processes. Plasma treatment for waste gas utilization [45] for acetylene production is developed as one of the first and most successful commercial applications of thermal plasma processing. Despite the background and a significant number of laboratory studies, the development of thermal plasma processes for gaseous and liquid waste streams has not 
met with the same degree of commercial success as solid treatment processes. However, that most solid waste treatment processes at some stage need to be treat their gaseous products, although not necessarily at high concentration levels. Fig. 13 shows the photocatalytic treatment of environmental pollutants. To develop a more effective and low-cost method for volatile organic compound decomposition, further extensive research using $\mathrm{TiO}_{2}$ photocatalytic system was performed. Discharge plasma is considered as a driving source of photocatalysis. Strong plasma is expected to promote the excited rate of electron on the surface of $\mathrm{TiO}_{2}$ catalyst compared with UV irradiation.

CSIRO Australia has reported the successful commercialization of PLASCON $^{\mathrm{TM}}$ technology for the treatment of liquid and gaseous waste. Commercial systems based on PLASCON process have been operation since 1992 and four units are currently used in Australia. Two systems are being used to destroy liquid chlorophenolic waste from an agricultural chemical plant, a third is treating the gaseous ozone depleting substance Halon 1211 and the fourth is treating polychlorinated biphenyls (PCBs).

The use of thermal plasma technology for the treatment of variety hazardous wastes, such as residues from municipal solid waste incineration, slag and dust from steel production, asbestos containing wastes, health care wastes and organic liquid wastes with potential application of plasma vitrified products [46]. The aim is to reduce fossil fuel consumption and increase waste treatment with both volume reduction and energy recovery process. Thermal plasma lead to decrease of re-emitted global $\mathrm{CO}_{2}$. North Italy (Turin) provinces utilized both electrical and thermal energy process for municipal waste treatment in economical and environmental process [47]. The gasification process for the treatment of municipal waste by thermal plasma technology offers economical price over 
electrical energy process [48]. Fig. 14 shows the thermal plasma process of pyrolysis unit for waste treatment. There have been continued advances in the application of plasma technology for waste treatment, and this is now a viable alternative to other potential treatment/disposal options. Red mud emerges as the major waste material during the production of alumina from bauxite by the Bayer's process. It compromises of oxides of iron, titanium, aluminum and silica along with some other minor constituents. Thermal plasma techniques make utilizable red mud as coating material. Thermal plasma spraying or red mud on material like aluminum, copper and steel induces the corrosive inhabitant property.

As thermal plasma process is very expensive depending on the electricity used and other process control factor, so it only uses for the destruction of toxic waste in compare to other processes. However the avoidance of landfill charges, the added value of the reuse of the vitrified product, recovery of metals and the energy production from syngas together will improve the commercial viability of this process.

\subsection{Thermal plasma technology on Coating, spraying}

It is the generic category of material processing technique that apply consumables in the form of a finely divided molten or semi molten droplets to produce a coating onto the substrate kept in front of the impinging jet. The melting of the consumables may be accomplished in a number of ways, and the consumable can be introduced into the heat source in wire or powder form. Thermal spray consumables can be metallic, ceramic or polymeric substances. Any material can be sprayed as long as it can be melted by the heat source employed and does not undergo degradation during heating. The nature of bonding at the coating-substrate interface is not completely understood. It is normally 
assumed that bonding occurs by the mechanical interlocking. Fig. 15 shows the common thermal plasma spraying. This is an extremely significant feature of thermal spraying. Another interesting aspect of thermal spraying is that the surface temperature seldom exceeds $200^{\circ} \mathrm{C}$. Hard metal or ceramic coating can be applied to thermosetting plastics. The spraying action is achieved by the rapid expansion of combustion gases (which transfer the momentum to the molten droplets) or by a separate supply of compressed air.

\subsection{Thermal plasma technology on metallurgical applications}

Plasma furnaces have a high melting efficiency, and are capable of producing alloys with low carbon, low hydrogen and low oxygen content. The transferred arc plasma devices used in metallurgical industry are characterized by high efficiency concentration, high thermal efficiency, excellent heat and mass transfer conditions, and adequate residence time. A number of processes were developed in which plasma is used as a source of chemically active species. Theses are mostly concerned with the plasma chemical synthesis of materials such as high purity synthetic silica, and ultrafine high purity ceramic powders and production of high purity titania slag from ilmenite [48]. The role of the plasma in each of these cases lies in its ability to heat the reactants to relatively high temperatures under well controlled conditions. Fig. 16 shows the thermal plasma processing slag metallurgy.

Such reaction systems use DC plasma torches, transferred arcs, RF induction plasma torches, and hybrid combinations. Gaseous precursors are by far the most commonly used due to their ease of handling and the control of the injection position in the reactor. Chemical species that are formed as stable products at high temperatures may undergo undesirable changes during gradual cooling to room 
temperature [49]. Product collection and handling is particularly critical in processes leading to the formation of ultrafine powders of high purity materials. Because of their submicron particle-size range (10-20 nm) and relatively high specific are (of the order of $20-80 \mathrm{~m}^{2} / \mathrm{g}$ ), most of these materials are rather sensitive to exposure to air and require handling and processing under an inert atmosphere [50]. A large number of materials have been prepared using thermal plasma technology. In a number of cases the processes developed lead to full scale industrial production. The super high rate thermal plasma CVD used a $25-\mathrm{kW}$ dc/RF hybrid plasma reactor with $\mathrm{SiCl}_{4}$ and $\mathrm{CH}_{4}$ as precursor under soft vacuum conditions. RF plasma flash evaporation has also been used for the deposition of as grown superconducting $\mathrm{Y}-\mathrm{Ba}-\mathrm{Cu}-\mathrm{O}$ films at rates of the order of $0.1-0.2$ $\mu \mathrm{m} / \min [51]$.

These advantages of thermal plasma determine the technical and economical efficiency of substituting the conventional technological routes by plasma routes based on electrical energy. Rising scarcity of fossil fuels and transportation difficulties tend to work out wider use of electrical energy and hydrogen for metallurgical processes. High economy of deficient fuels coke, natural gas and oil is becoming conceivable. As expected in 25-50 years time the gradual substitution of thermal energy from hydrocarbon fuels with electric energy generated in coal or nuclear power stations as well as by hydrogen energy favours the use of thermal plasma for pyro metallurgical processes. The possibility of realizing thermal plasma processes depends on the development of the appropriate equipment such as the plasma generators, furnaces and reactors. The general requirements of process engineers are sufficient power, the possibility of utilizing active gases such as hydrogen, oxygen, chlorine, argon and methane and a long service life. 
The most prospective route is to use thermal plasma for reducing metal oxides, which are intermediate products of the final stage of the metallurgical application [52]. The main limitation of the thermal plasma processes are

- A short residence time of raw material staying in high temperature zone (0.1$10 \mathrm{~S})$

- High energy consumption due to water-cooling of the plasmatron reactor parts

- Heat loss with waste gases

- The melt in high temperature zone is moving slower than disperse particles in jet.

Residence time of the melt in the high temperature reaction zone can be controlled by the selection of the process parameters. Disperse raw material being directly injected into discharge zone may disrupt its stability and lower thermal efficiency. Energy consumption of plasma process may be lower than for traditional technology due to increased out put and equipment miniaturization. Fig. 16 shows the thermal plasma process for metallurgical application for recovery of slag from mineral [53].

Present status in research and technology for thermal plasma application in metallurgy

- By means of thermal plasma technology it is possible to produce both cast metal and metallic powders, including highly dispersed and spherodal, and material with single crystal and multi-layered structure, alloys, pseudoalloys and composites.

- Thermal plasma technology may enable to design compact and easily managed plants with high level of process mechanization and automation. A reduction in the dimensions and metal consumption of production process equipment and correspondingly in capital investment may also be expected. 
- Reduce threat to the environment. With increase in plant specific productivity the water consumption and waste water discharge should decrease substantially.

- Industrial realization of small scale plasma processes such as welding, cutting, surface coating, powder production, synthesis of oxides and carbide, nitrides.

\subsection{Thermal plasma synthesis of nano particles}

The radio frequency inductively coupled thermal plasma synthesis process, based on the use of solution precursors as the process feedstock, and has been employed for the production of nano powders. Recently, an innovative plasma processing technique has been developed for the preparation of nano sized powders by vapour phase reaction. The thermal plasma process provides a high processing rate as well as many other advantages for the synthesis of nano sized powders such as a high processing temperature to vapourize all reactants, a clean reaction atmosphere that yields high purity products, a high quench rate to form fine powders and a wide range of reactants. Thus, research on thermal plasma synthesis at ceramics and composites in recent years has given a new direction and impetus too many industrial applications as one of the most promising methods for producing nano sized powders [54]. Fig. 17 (thermal plasma with RF installation), Fig. 18 shows the schematic diagram of a plasma reactor system for nano particle formation.

\subsection{Thermal plasma densification}

Spheroidization and densification occur simultaneously as porous, irregularly shaped agglomerates are injected into thermal plasma. As the particles sinter and/or melt in the plasma, formed spherical shape and densify simultaneously. Commercially, fine particles are spheroidized in plasma for a variety of applications, including materials with a 
controlled porosity, catalysts, abrasives, and materials used for powder metallurgy. Plasma densification of pre-sintered agglomerates of metals (e.g., W, Mo) and carbidemetal mixtures (e.g., WC-Co) has been used to produce spherical, densified powders. Such powders possess excellent flow ability, which is beneficial to subsequent thermal coating operations [55]. Fig. 19 shows the schematic diagram of various thermal plasma centrifugal furnaces for densification process. Thermal plasma now becomes not only an object of laboratory research and experimental development, but also a real means tool for solving metallurgical problems. Sintering of high technology ceramics in thermal plasmas has the potential of drastically reducing the time period required for this process, compared with conventional technology. In addition, plasma sintering offers the opportunity for restrained grain growth and for tailoring heat transfer during the sintering process, which may result in desirable structures and properties of the sintered materials. The essential characteristics of plasma sintering and of any other sintering process are an increase in density and strength of a powder compact on heating. Plasma sintering is a process that may cover a pressure range from 760 to a few Torr. For pressures below 75 Torr, the plasma may no longer be classified as thermal plasma because of substantial deviations from local thermodynamic equilibrium.

\section{Future Vision}

Taking consideration to product obtained from waste as well as eco-friendly issues, thermal plasma process may be come out as viable in commercial market. The growth of thermal plasma technique may improve with possible redemption 
1. Lack of fundamental knowledge in this direction as it creates the lack of control on the thermal plasma reactors. As the process parameters are the main factor for yielding as well as energy consumption.

2. Power consumption is the basic source for thermal plasma reactor. Analysis of process parameters with compatible on the reactor will increase the productivity and decrease the power consumption.

3. Thermal plasma technology on metallurgy industries needs to model the appropriate data, theoretically before going to produce the set on experimental work.

\section{Conclusions}

The present status of application of thermal plasma in various areas is discussed. The generation, types of plasma system and temperature and power consumption covers up the various categories of plasma generation. Utilization of thermal plasma in materials synthesis from micro to nano level range from metal to ceramics is discussed briefly. The present status of research and development activities in each areas of thermal plasma application is discussed. The barriers and obstacles were discussed that holds thermal plasma being applicable in commercial ways. The output of thermal plasma techniques and its significant advantages in materials processing areas are covered up. Finally a future vision on the commercialization of thermal plasma technique is proposed on keeping the view on industrial benefits and its economic wise utilization.

\section{Acknowledgements}

Author would like to acknowledge University of Rennes 1, France for publication of this work. 


\section{References}

1. Plasma processing of Materials, National Academy of Press, Washington D.C, 1991, International Standard Book Number 0-309-04597-5.

2. S Elizer, Y Eliezer, The Fourth State of matter an Introduction to Plasma Science. IOP publishing. (2001).

3. D. A. Donaldson, R.R .Apa, T.L. Eddy and J.E. Flinn: 'Heat Transfer in Thermal Plasma Processing', HTD-161, ASME, 199, 41-51.

4. Introduction to Plasma Technology: Science, Engineering and Applications. John Harry, Copyright 2010 WILEY-VCH Verlag GmbH \& Co. KGaA, Weinheim ISBN: 978-3-527-32763-8.

5. P. Fanchais and J.M. Baronnet: 'State of the art of plasma chemical synthesis of homogeneous and heterogeneous products', Pure and Appl. Chem., 1980, 1669-1705.

6. D. Schriver,M. Ashour-Abdalla,R. L. Richard, On the origin of the ion-electron temperature difference in the plasma sheet, Journal of Geophysical research, Volume 103, Issue A7, 1 July 1998 , Pages 14879-14895.

7. T. Yoshida: 'Combustion and Plasma Synthesis of High Temperature Materials' (eds. Z.A. Munir and J.B. Holt), VCH Publishers, New York, NY; 1990, 328-339.

8. A.J. Becker, T.N. Meyer, E. N. Smith and J.E. Edd: 'Plasma Processing and Synthesis of Materials' (eds. D. Apelian and J. Szekely), Pittsburgh, PA: MRS-98, $1987,335-346$.

9. R. Burkhard, W. Hoffelner, R.C. Eschenbach, Recycling of metals from waste with thermal plasma, Resources, Conservation and Recycling, Volume 10, Issues 1-2, April 1994, Pages 11-16.

10. P.A. Warrendale: 'Plasma Technology in Metallurgical Processing', ISS-AIME. Processing ((ed. N. E1-Kaddah), TMS-AIME, 1987, 55-72. 
11. R.C. Kong and Y.C. Lan: 'Plasma synthesis of ceramic powders', Pure \&Appl. Chem., 62, 1990, 1809-1816.

12. W.C. Roman: 'Plasma Processing and Synthesis of Materials', (eds. J. Szekely and D. Apelian), NY: MRS-30, 61-75; 1984, Elsevier, New York.

13. M.E. Schlienger and M.P. Schlienger: 'Proceeding-Processing Materials for Properties' (eds. H. Henein and T. Oki), 1069- 1072; TMS, 1993.

14. R. Taylor Patrick and A. Pirzada Shahid: 'Thermal Plasma Processing of Materials: A Review', Advanced Performance Materials, 1, 1994, 35-50.

15. G. Bonizzoni, E. Vassallo: 'Plasma physics and technology; industrial applications', Vaccum, 64, 2002, 327- 336.

16. S.M.L. Hamblyn: 'Plasma technology and its application to extractive metallurgy', Miner. Sci. Eng., Vol.9, No.3, July 1977, 151-176.

17. S.E. Stenkvist and B. Bowman: 'High-power, graphite-cathode DC arc plasma properties and practical applications for steelmaking and ferroalloys processing', Plasma technology in Metallurgical Processing, The Iron and Steel Society, AIME, 1987, Chapter 8B, 103-109.

18. P.C. Pistorius and C. Coetzee: 'Physicochemical aspects of titania slag production and solidification', Metallurgical and Materials Transaction B, Vol.34 B, Oct.2003.

19. N.A. Barcza, T.R. Curr and U. K. Maske: 'The application of thermal plasma technology to large-scale pyrometallurgical processes', Extraction Metallurgy '85, Institute of Mining and Metallurgy, London, June 1985, 709-740.

20. A.F.S. Schoukens, L.R. Nelson and N.A. Barcza: 'Plasma-arc treatment of steel-plant dust and zinc-containing slag -- theoretical and practical considerations', Recycling Lead and Zinc, The Challenge of the 1990's, International Lead and Zinc Study Group, London, 1991, 361-370.

21. U. Hütter: 'Refractories and conductive bottom design for DC-arc furnaces', system ABB, Radex-Rundschau, 1992, Vol.2/3, 83-95. 
22. E. Gomez, D. Amutha Rani, C.R. Cheeseman, D. Deegan, M. Wise and A.R.

Boccaccini: 'Thermal Plasma technology for the treatment of wastes: A critical Review', Journal of Hazardous Materials, 2009,161, 614-626.

23. J. Heberlein, O. Postel, S. Girshick, P. McMurry, W. Gerberich, D. Iordanoglou, F. Di Fonzo, D. Neumann, A. Gidwani, M. Fan, N. Tymiak, Thermal plasma deposition of nanophase hard coatings, Surface and Coatings Technology 142-144 (2001) 265-271.

24. Javad Mostaghimi, Maher I. Boulos, Thermal Plasma Sources: How Well are They Adopted to Process Needs? Plasma Chemistry and Plasma Processing, May 2015, Volume 35, Issue 3, pp 421-436.

25. Díaz V., Dutra J.C., D’Oliveira A.S.C.: Hard facing by plasma transferred arc process. In: W. Sudnik (Ed.), InTech, Available from: http://www.intechopen.com/books/arc-welding/hardfacing-by-plasma-transferred-arcprocess

26. K. J. Hollis, R. G. Castro, B. D. Bartram, Transferred-Arc Cleaning of Tungsten, LAUR-99-5783, http://lib-www.lanl.gov/la-pubs/00796481.pdf

27. A M Paingankar, A K Das, V S Shirodkar, K P Sreekumar and N Venkatramani, Prediction of electrical characteristics of anon-transferred arc-plasma torch using principles of dynamic similarity, Plasma Sources Science and Technology, volume 8, 1, (1999).

28. Georg Mauer, Robert Vaßen, Detlev Stöver, Plasma and Particle Temperature Measurements in Thermal Spray: Approaches and Applications, Journal of Thermal Spray Technology, March 2011, Volume 20, Issue 3, pp 391-406.

29. J.V.R. Heberlein, Generation of thermal and pseudo-thermal plasmas , Pure \& Appl. Chem.,Vol.64,No. 5, pp.629-636,1992.Printed in Great Britain.1992 IUPAC

30. Yuri Akishev, Michail Grushin, Anatoly Napartovich, Nikolay Trushkin ,Novel AC and DC Non-Thermal Plasma Sources for Cold Surface Treatment of Polymer Films and Fabrics at Atmospheric Pressure, Plasmas and Polymers, September 2002, Volume 7, Issue 3, pp 261-289. 
31. Arjen Boogaard, Plasma enhanced chemical vapour deposition of silicon dioxide: optimizing dielectric films through plasma charcaterization, ISBN : 978-90-365-3130-6, DOI: $10.3990 / 1.9789036531306$.

32. Muhammad Arif Malik, David Hughes, Richard Heller, Karl H. Schoenbach, Surface Plasmas Versus Volume Plasma: Energy Deposition and Ozone Generation in Air and Oxygen, Plasma Chem Plasma Process (2015) 35:697-704 , DOI 10.1007/s11090-015-96113.

33. J.Leon Shohet, Plasma-Aided manufacturing, Ieee Transactionson Plasma Science, Vol 19,No 5,October 1991.

34. S Cho, H Shim, K So, S Kim, S Samal, D Park, H Kim, Synthesis of nanosized glass powders using non-transferred dc thermal plasma process, Advances in Applied Ceramics 112 (5), 2013, 288-293

35. Patrick R. Taylor, Shahid A. Pirzada, Thermal Plasma Processing of Materials: A Review , Advanced Performance Materials, 1, 35-50 (1994)

36. S Samal, P. S Mukherjee, AK Ray, Comparative study on energy consumption and yield by various thermal plasma routes for production of titania slag, Plasma Chemistry and Plasma Processing 30 (3), 413-428.

37. M. Mihovsky, Thermal Plasma Application in Metallurgy (REVIEW), Journal of the University of Chemical Technology and Metallurgy, 45, 1, 2010, 3-18.

38. R.T. Jones ,N.A. Barcza ,T.R. Curr, Plasma Developments in Africa, http://www.pyrometallurgy.co.za/Mintek/Plasma/Plasma.htm.

39. Graphite electrode DC arc furnace, Innovative technology summary report DOE/EM 0431.

40. Mu-Gap Shin, Dong-Wha Park, Synthesis of copper nanopowders by transferred arc and non-transferred arc plasma systems, Journal of Optoelectronics and Advanced materials, Vol. 12, no. 3, March 2010, p. $528-534$. 
41. Sneha Samal, Dong-Wha Park, Nano-particle synthesis of titanium oxides from ilmenite in a thermal plasma reactor, Chemical Engineering Research and Design, Volume 90, Issue 4, April 2012, Pages 548-554.

42. P.S. Mukherjee, S. Samal and T.K. Mukherjee: 'Effect of processing parameters on production of $\mathrm{TiO}_{2}$ rich slag \& iron from metallized ilmenite in a moving bed reactor' Min. Process. Extract. Metall. (Trans. Inst. Min. Metall. C), 2006, Vol.115, No. 4, 224-228.

43. P.S. Mukherjee, S. Samal and T.K. Mukherjee: 'In-flight thermal plasma processing of pre-reduced oscom ilmenite of varying degree of metallization', Trans. Indian Inst. Met., June 2006, Vol.59, No.3, 353-358.

44. Sneha Samal, Dong-Wook Kim, Kyo-Seon Kim, Dong-Wha Park, Direct synthesis of $\mathrm{TiO}_{2}$ nanoparticles by using the solid-state precursor $\mathrm{TiH}_{2}$ powder in a thermal plasma reactor, Chemical Engineering Research and Design, Volume 90, Issue 8, August 2012, 1074-1081

45. D. Panepinto, G. Genon, Solid waste and biomass gasification: fundamental processes and numerical simulation, Chemical Engineering Transactions, (2011), 24:25-30.

46. Deborah Panepinto and Giuseppe Genon, Waste Management \& Research, 2014, Vol. 32(7) 670-680.

47. Deborah Panepinto, Annamaria Senor, Giuseppe Genon, Energy recovery from waste incineration: economic aspects, Clean Techn Environ Policy (2016) 18:517-527

48. S. Samal, P.S. Mukherjee, K.K. Rao, P. Chattopadhyay and T.K. Mukherjee:

Statistical modelling studies on leachability of titania rich slag obtained from Plasma melt separation of metallized Ilmenite', Chemical Engineering research and Design, 2008, 86 , 187-191.

49. S. Samal, K. K. Rao and P.S. Mukherjee, 'Optimization of titanium dioxide rich slag production using statistics based experimental designs in a moving bed plasma reactor', Min. Process. Extract. Metall. (Trans. Inst. Min. Metall. C), 2009, Vol.118, No.1, 2-9.

50. S. Samal, B. K. Mohapatra, S. K. Chatterjee and P. S. Mukherjee, 'Integrated XRD, EPMA and XRF study of ilmenite and titania slag used in pigment production' Journal of Alloys and Compounds, 2009, 474, 484-489. 
51. X. W. Wang, H. H. Zhong R. L. Snyder, Superconducting $\mathrm{Y}_{1} \mathrm{Ba}_{2} \mathrm{Cu}_{3} \mathrm{O}_{7-\delta}$ Films by RF Plasma Aerosol Evaporation at Atmospheric Pressure, Science and Technology of Thin Film Superconductors 2, pp 311-317.

52. S. Samal, P. S. Mukherjee \& T. K. Mukherjee, Thermal plasma processing of ilmenire : a review, Mineral processing and extractive metallurgy, vol. 119, issue 2, 2010, pp. 116-123.

53. G. Bolelli, V. Cannillo, C. Lugli, L. Lusvarghi',T. Manfredini, Plasma-sprayed graded ceramic coatings on refractory materials for improved chemical resistance, Journal of the European Ceramic Society, Volume 26, Issue 13, 2006, Pages 2561-2579.

54. Lu Jia, François Gitzhofer, Nano-Particle Sizing in a Thermal Plasma Synthesis Reactor, Plasma Chemistry and Plasma Processing, December 2009, 29:497

55. Pierre Fauchais, Ghislain Montavon, and Ghislaine Bertrand, From Powders to Thermally Sprayed Coatings, JTTEE5 19:56-80, DOI: 10.1007/s11666-009-9435-x. 
Table 1. Summary table for characteristics of plasma.

\begin{tabular}{cc|c}
\hline \multicolumn{2}{c|}{$\begin{array}{c}\text { Low-temperature plasma } \\
\text { (LTP) }\end{array}$} & $\begin{array}{c}\text { High-temperature plasma } \\
\text { (HTP) }\end{array}$ \\
\hline Thermal LTP & Nonthermal LTP & \\
$T_{e} \approx T_{i} \approx T \lesssim 2 \times 10^{4} \mathrm{~K}$ & $T_{i} \approx T \approx 300 \mathrm{~K}$ & $T_{i} \approx T_{e} \gtrsim 10^{7} \mathrm{~K}$ \\
& $T_{i} \ll T_{e} \lesssim 10^{5} \mathrm{~K}$ & \\
e.g., arc plasma & e.g., low-pressure & e.g., fusion plasmas \\
at normal pressure & glow discharge & \\
\hline
\end{tabular}

\section{Figures}

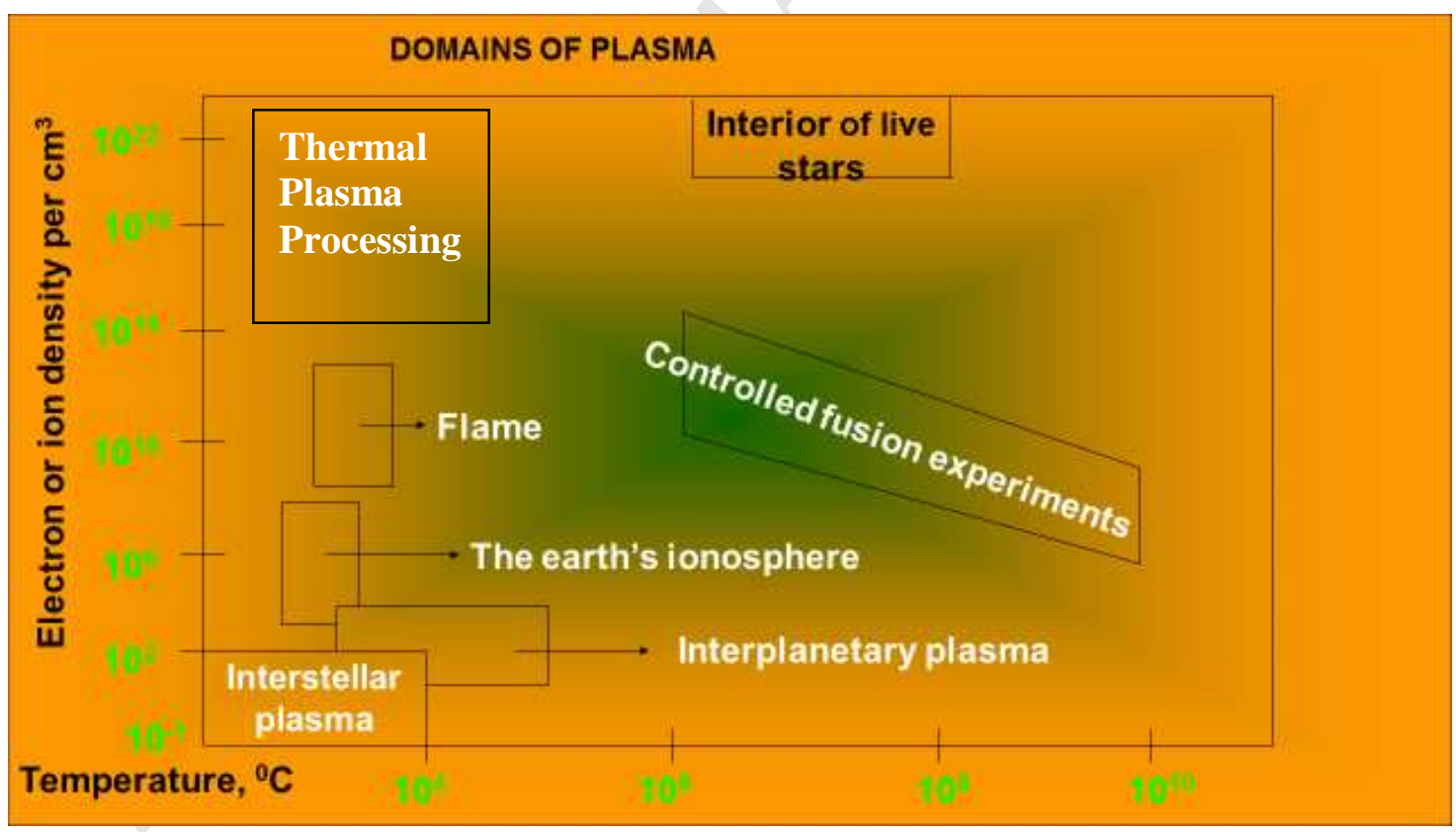

Fig. 1. Domains of plasma as the function of temperature and elctron density. 


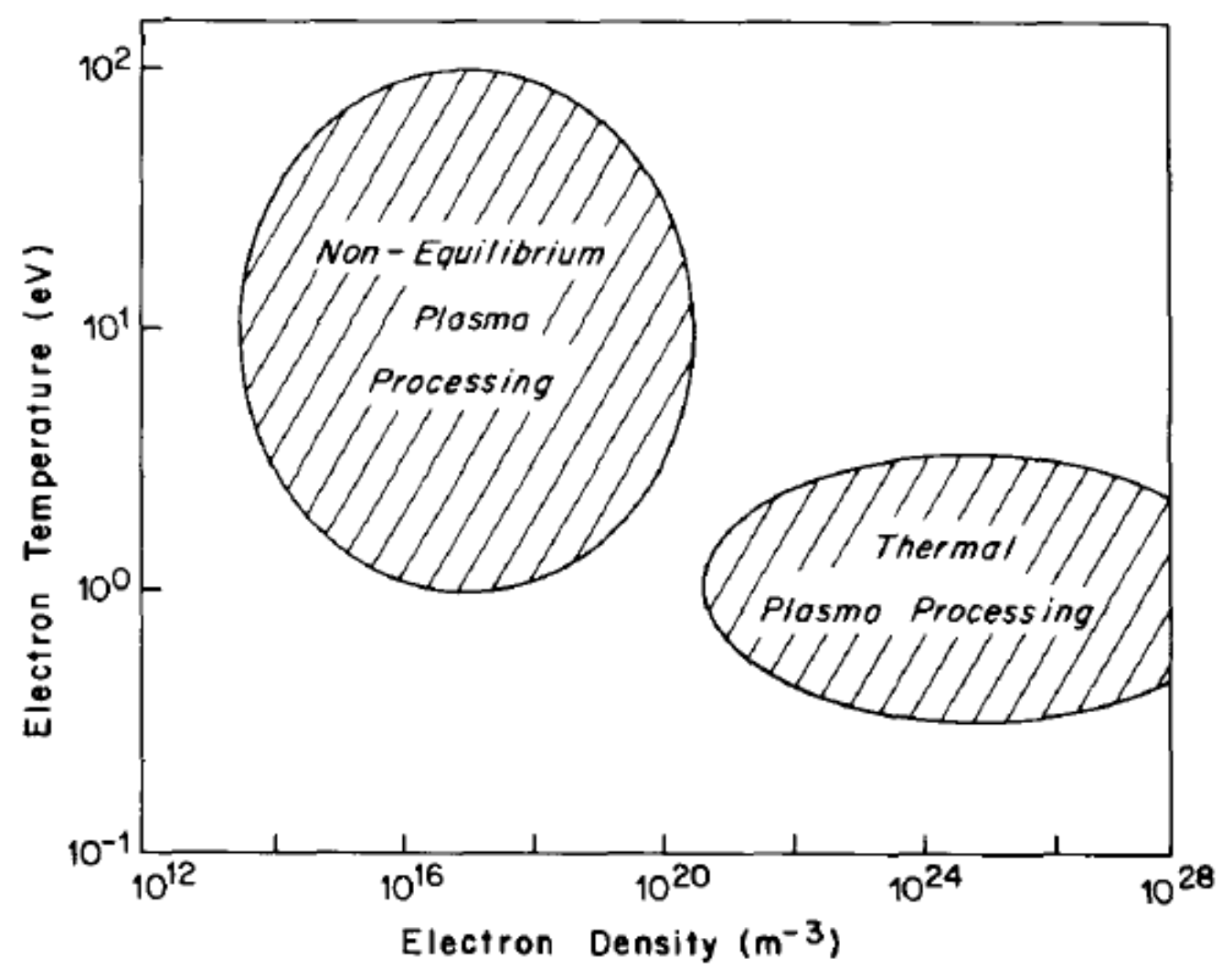

Fig. 2. Typical ranges of electron temperature range with elctron density for non equilibrium and equilibrium plasma processing system. 


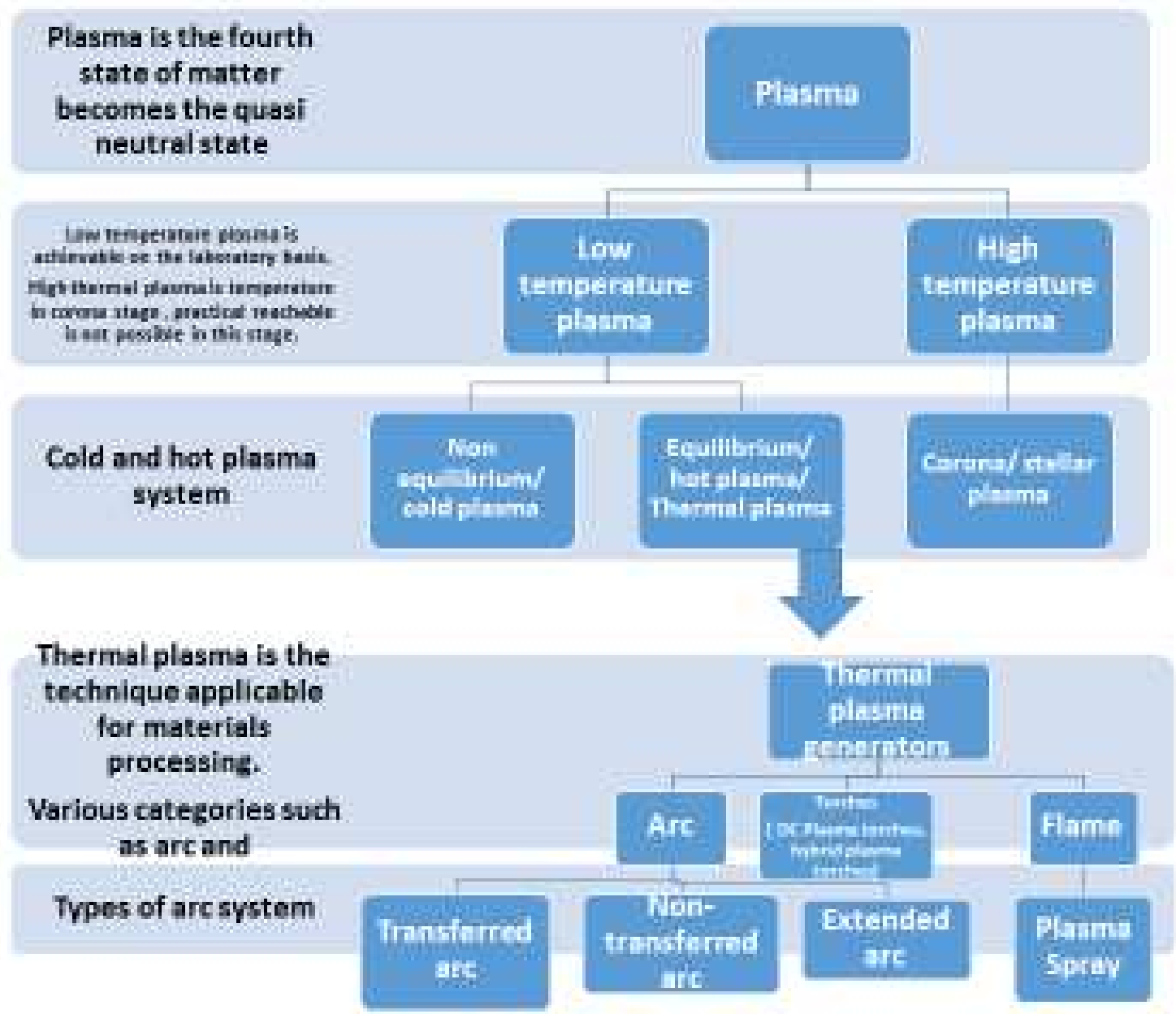

Fig. 3. Categries of plasma system 


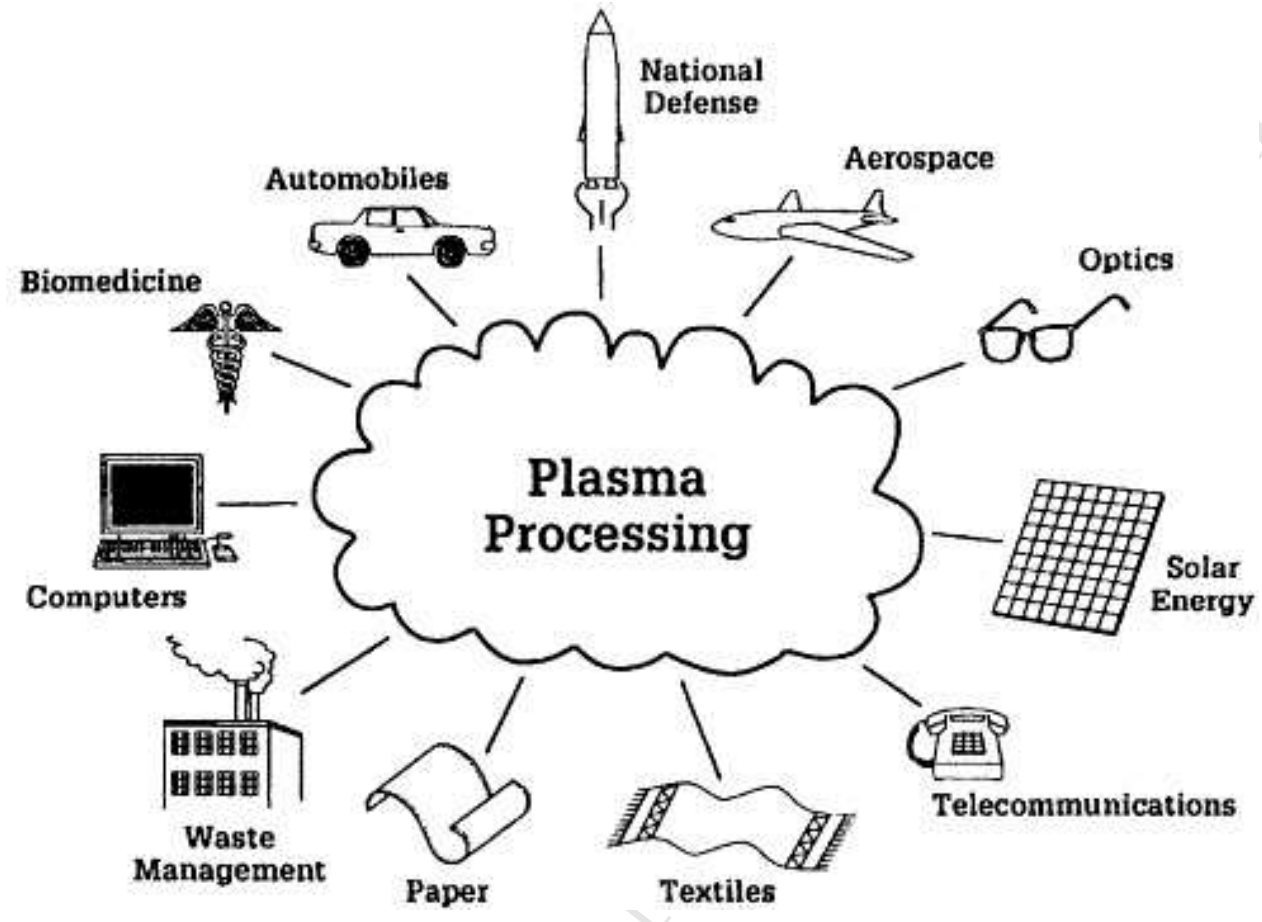

Fig. 4. Application of plasma in various areas from to high cost technology. 

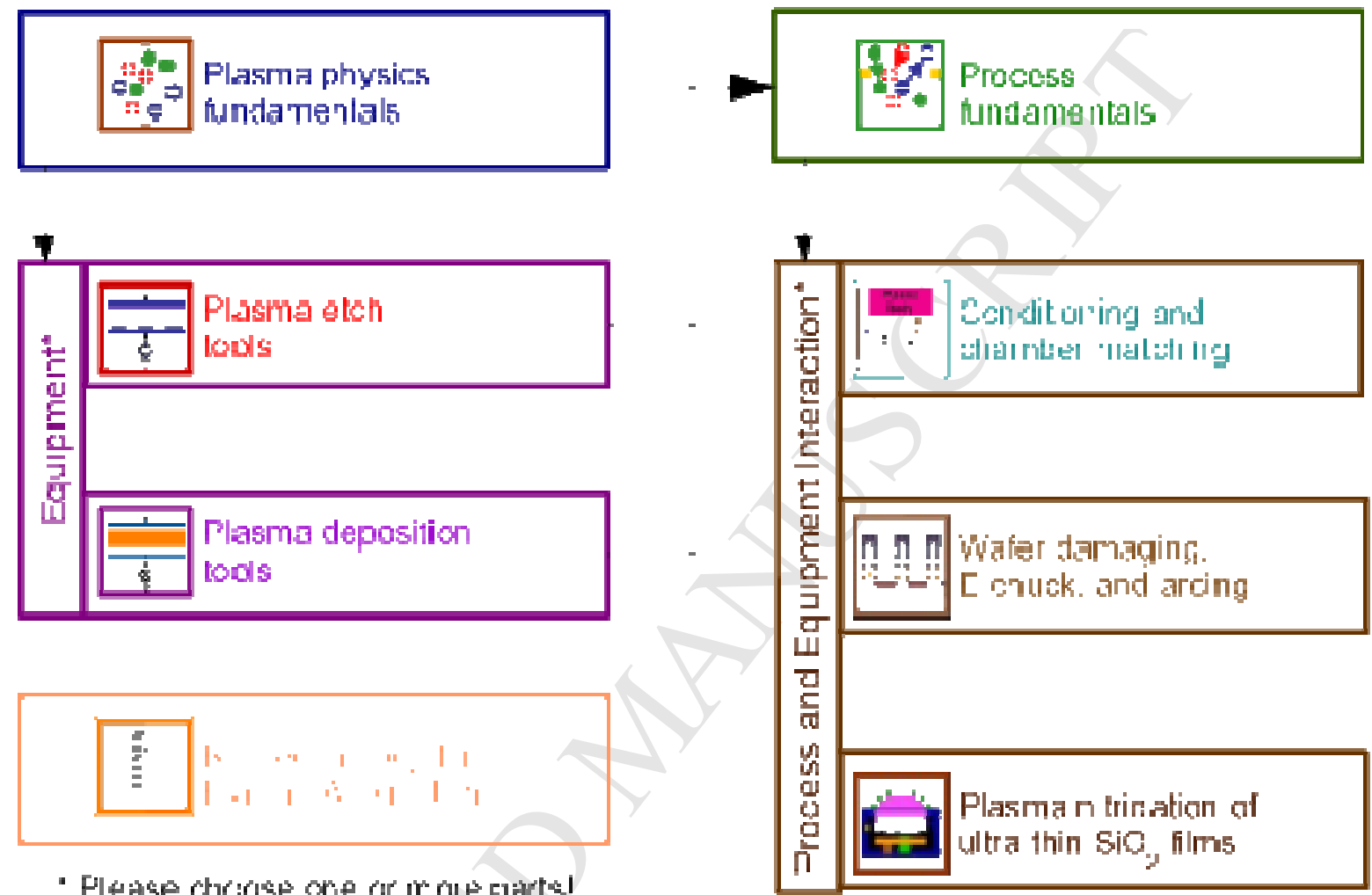

- Fitease chcose one ar ir on parts!

Fig. 5 Various categories of plasma manufacturing processes.

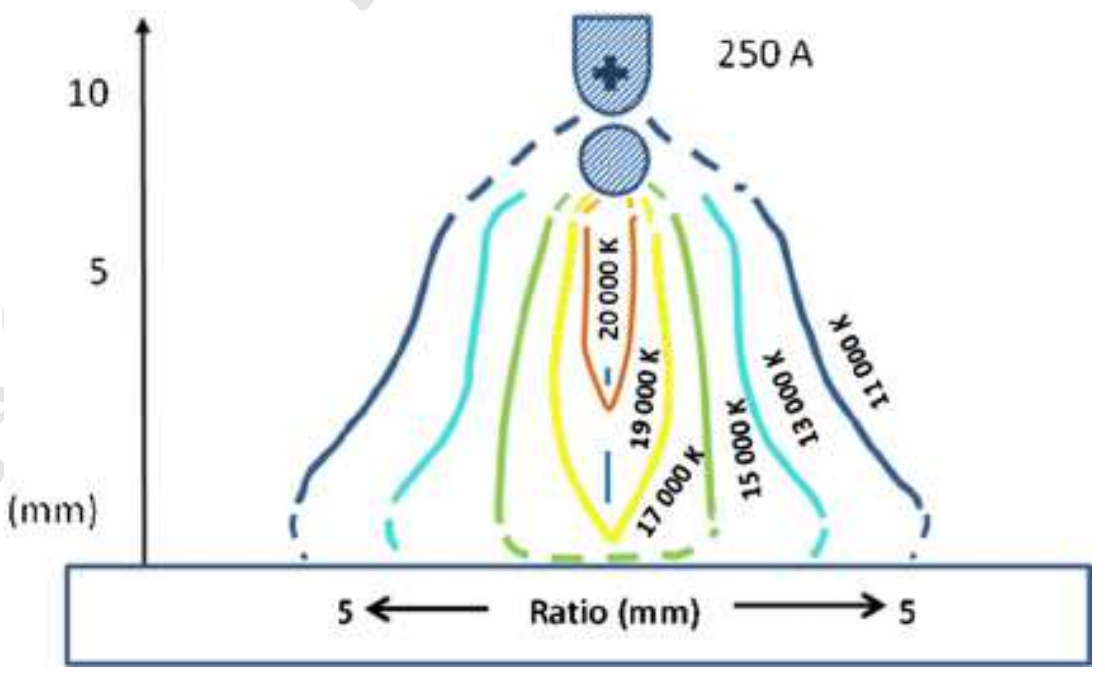

Fig. 6. Various zone of temperature distribution in arc thermal plasma . 


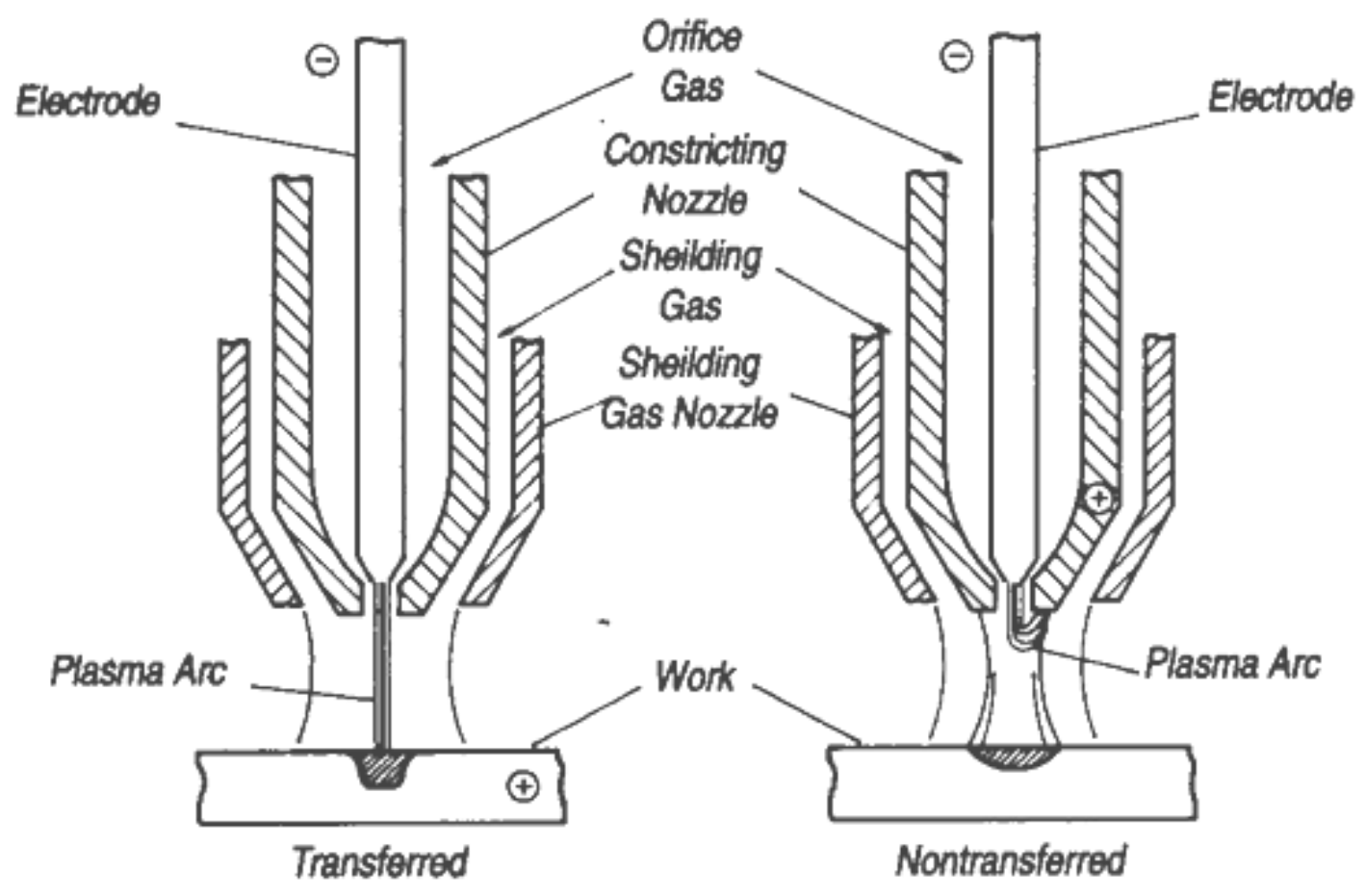

Fig. 7 Schematic diagram of transferred and non transferred arc reactors. 

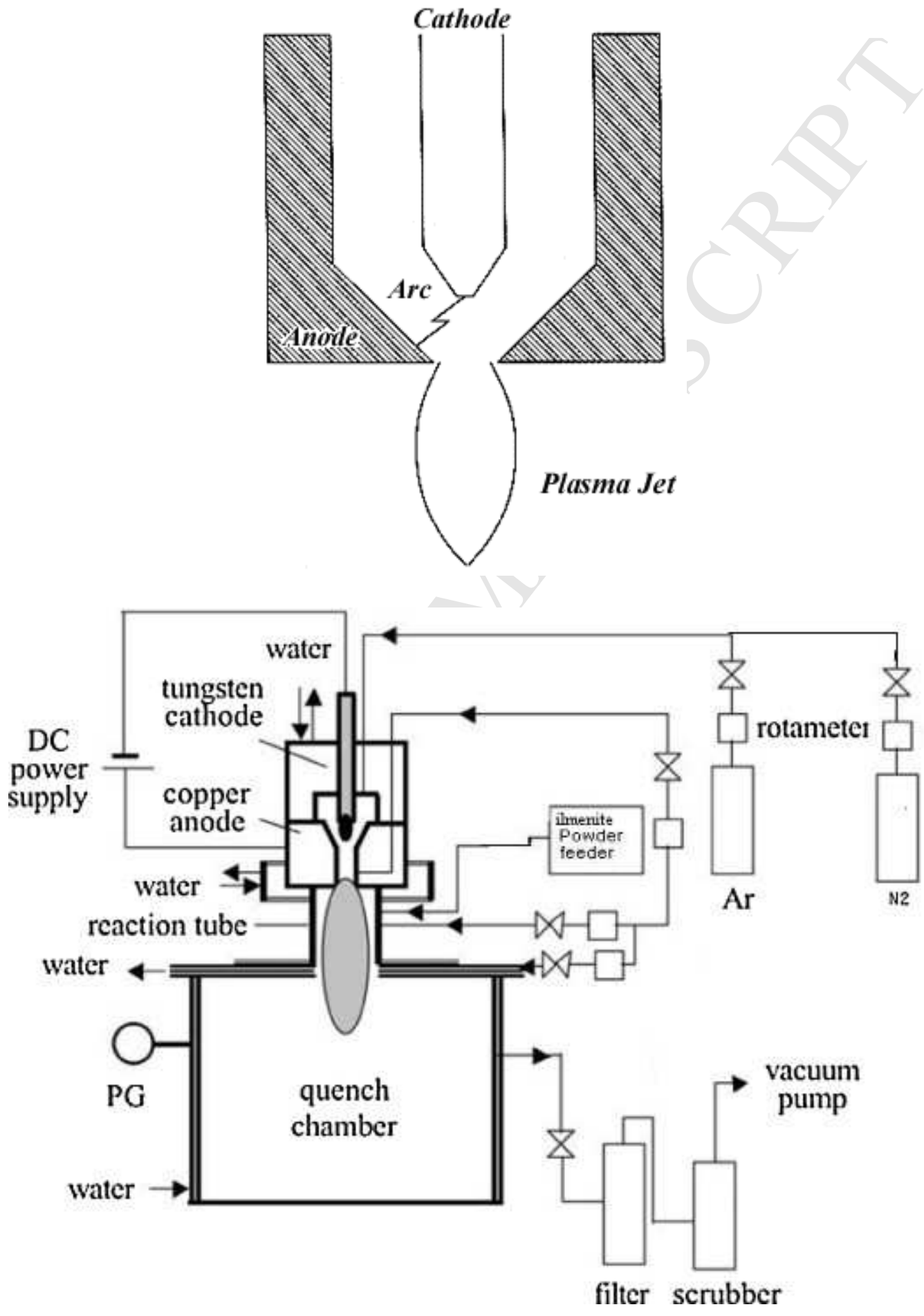

Fig. 8 Schematic diagram and example of non transferred arc reactor. 


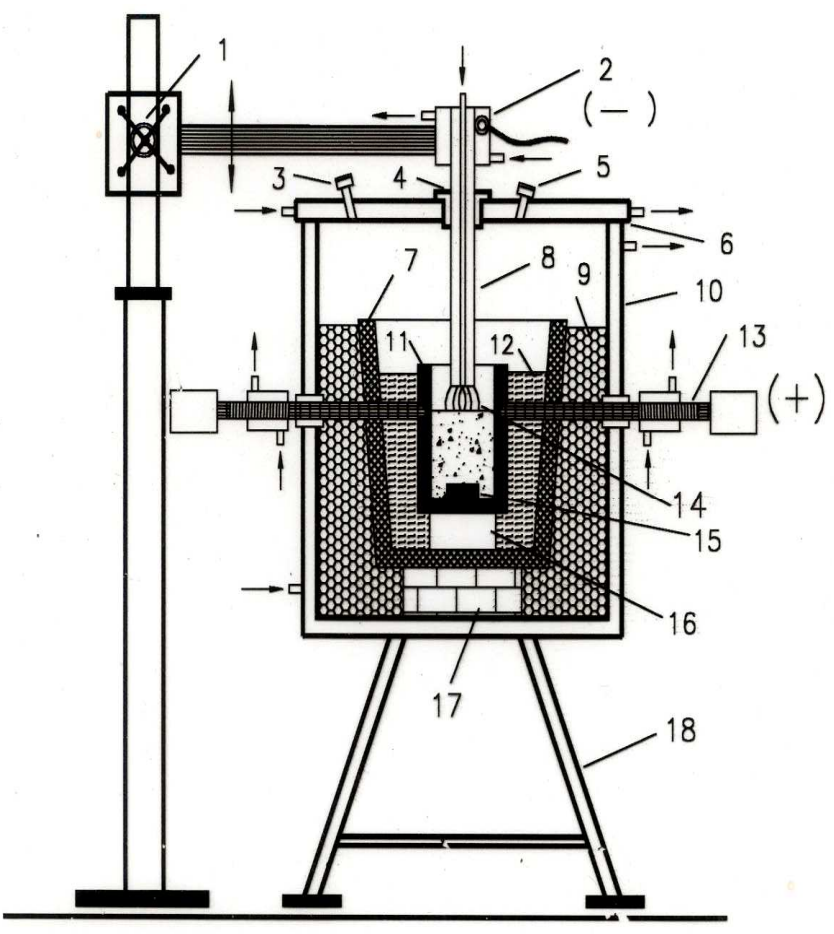

1. Rack and pinion

2. Electrode holder with water cooling

3. Gas exhaust outlet

4. Alumina bush with graphite sleeve

5. Viewing port

6. Water cooled steel cover

7. Salamander hearth

8. Graphite electrode

9. Bubble alumina
10. Water cooled steel casing

11. Graphite crucible

12. Graphite wool

13. Water cooled graphite electrode

14. Plasma

15. Graphite block

16. Magnesia block

17. Alumina block

18. Supporting structure

Fig. 9 Schematic diagram of transferred arc reactor of thermal plasma process: Static bed reactor 


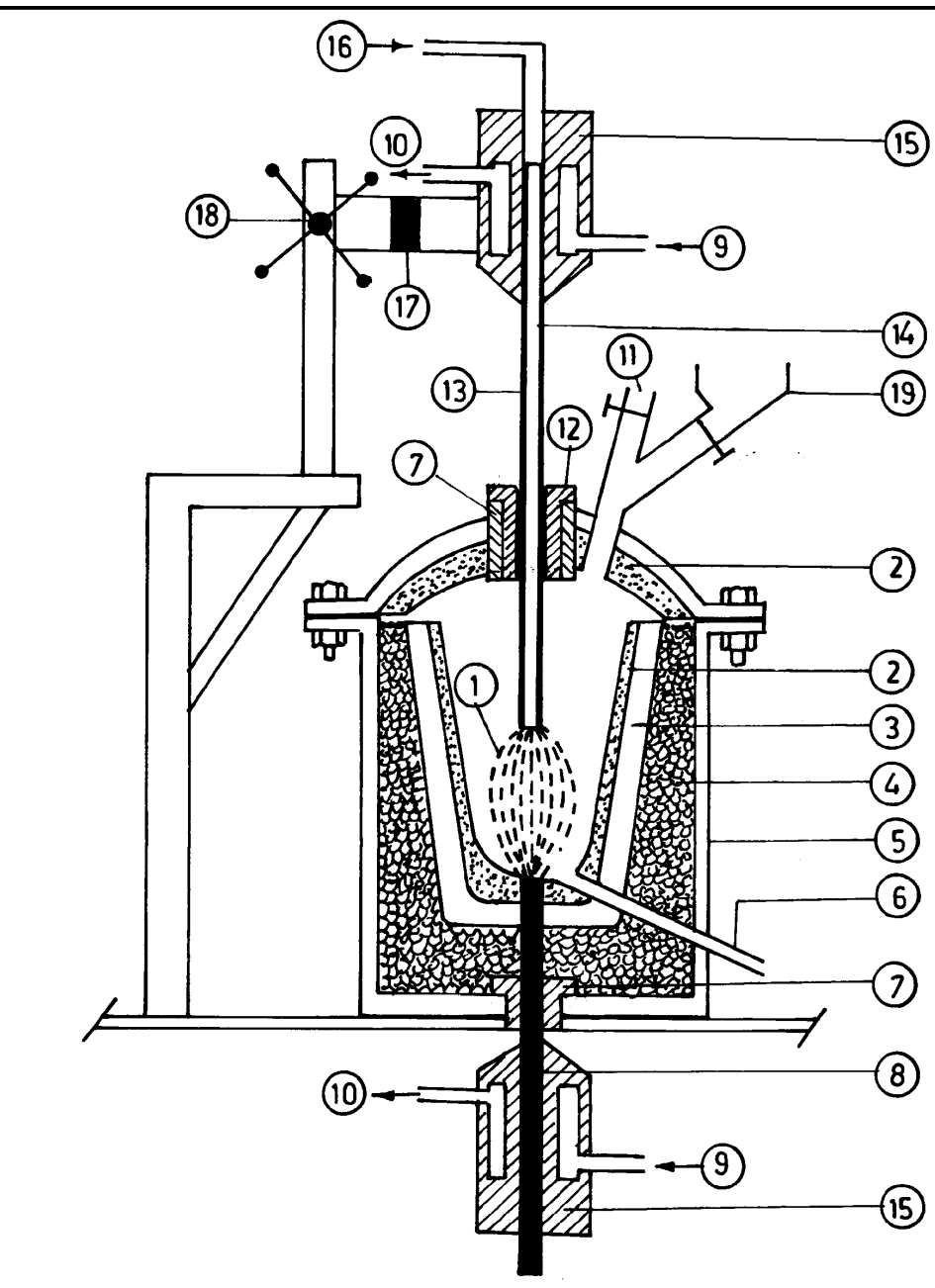

1. Plasma 2. Magnesia Coating 3. Graphite Crucible 4. Bubble Alumina 5. M.S. Casing. 6. Tap hole 7. Alumina Bush 8. Bottom Graphite Electrode 9. Water Inlet 10. Water Outlet 11. Outlet for Exhaust Gases 12. Graphite Sleeve 13. Top Graphite Electrode 14. Axial Hole 15. Copper Block 16. Plasma Forming Gas 17. Electrical Insulation 18. Rack \& Pinion Mechanism 19. Hopper

Fig. 10 Schematic diagram of transferred arc reactor of thermal plasma process: inflight direct current extended arc plasma reactor. 


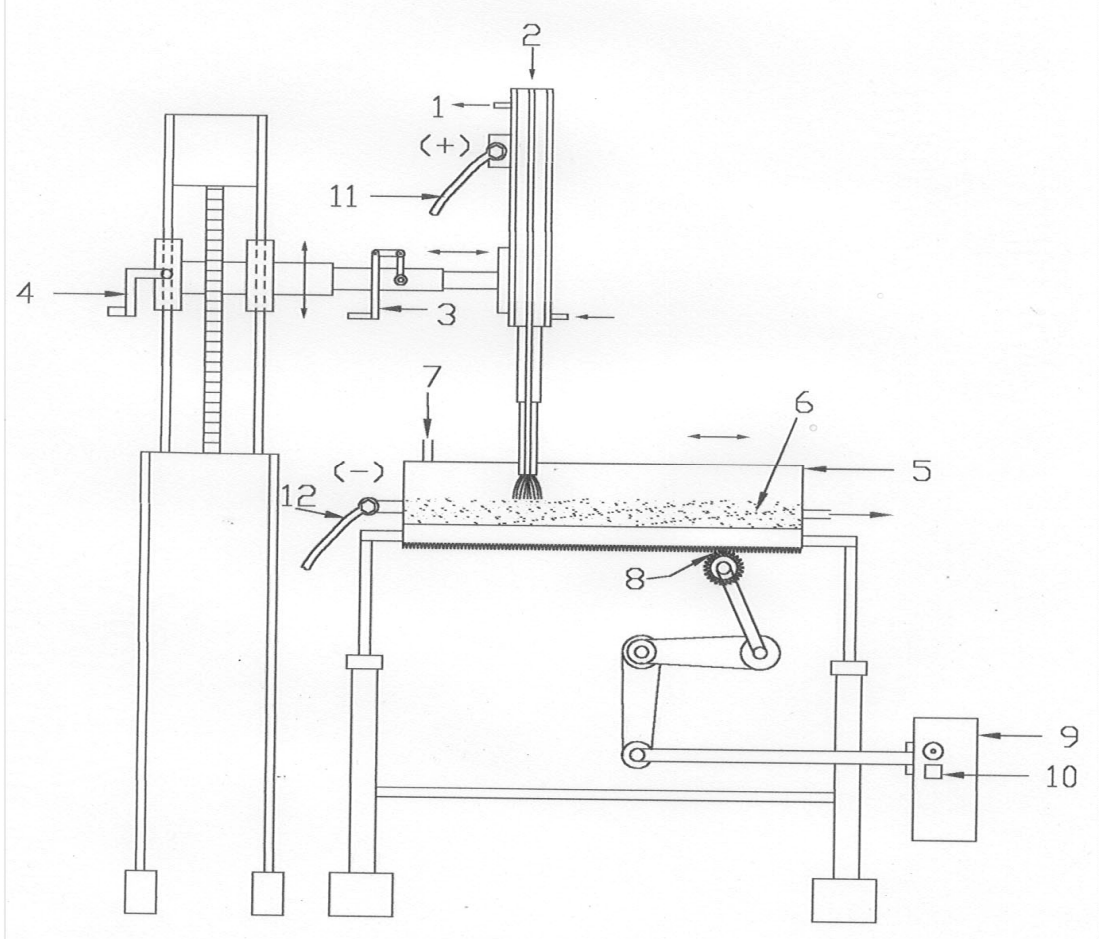

Fig. : Schematic diagram of Moving bed Reactor

1. Water cooling system for cathode

2. Hollow graphite electrode, cathode

3. Lever for horizontal movement of the cathode

4. Lever for vertical movement of the cathode

5. Tray for holding the charge

6. Charge (Metallized Ilmenite)

7. Water cooling system for the tray

8. Rack and pinion arrangement

9. Gear box

10. AC motor

Fig. 11 Schematic diagram of transferred arc reactor of thermal plasma process: moving bed reactor 


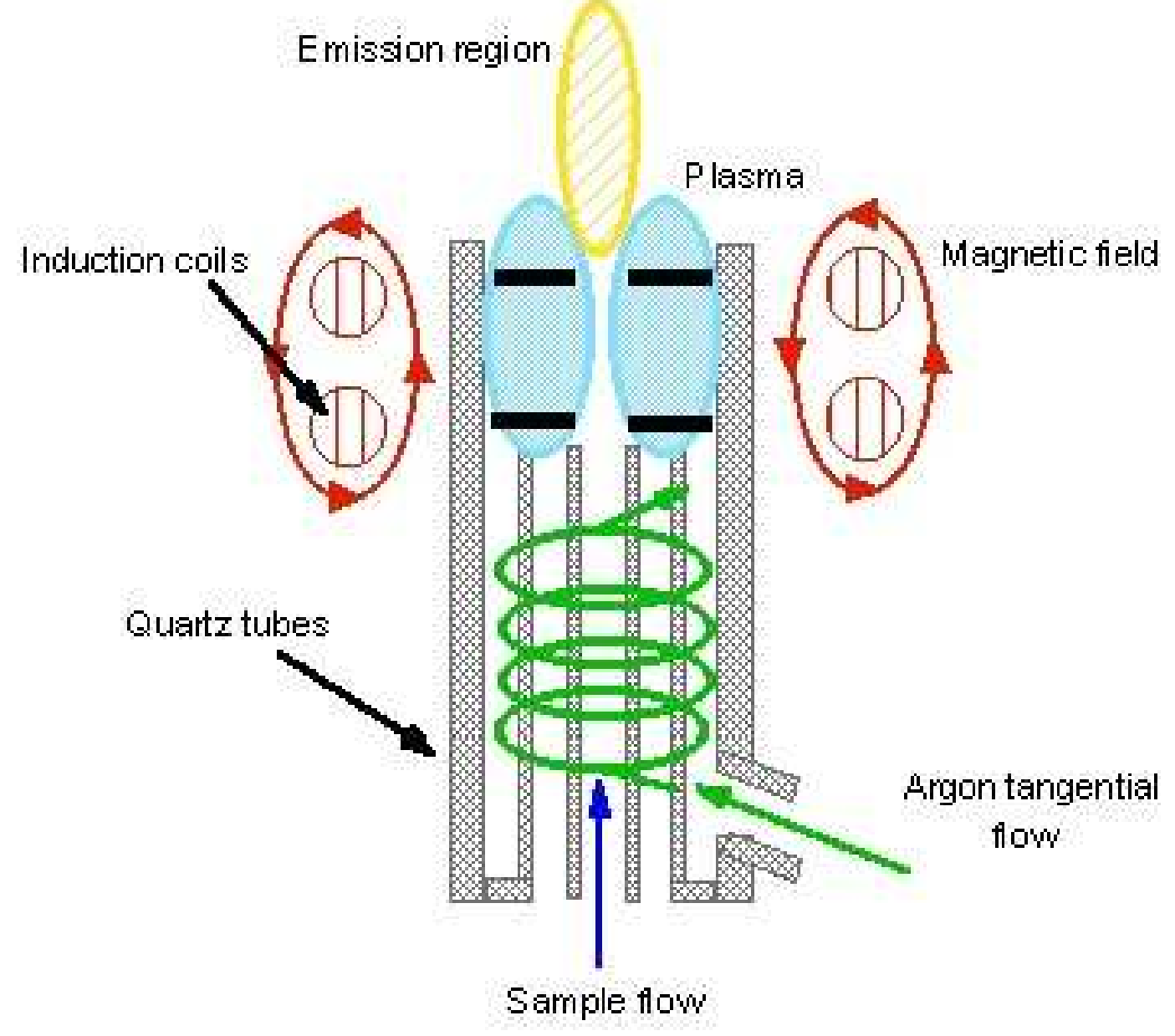

Fig. 12 Schematic diagram of RF inductively coupled discharge 


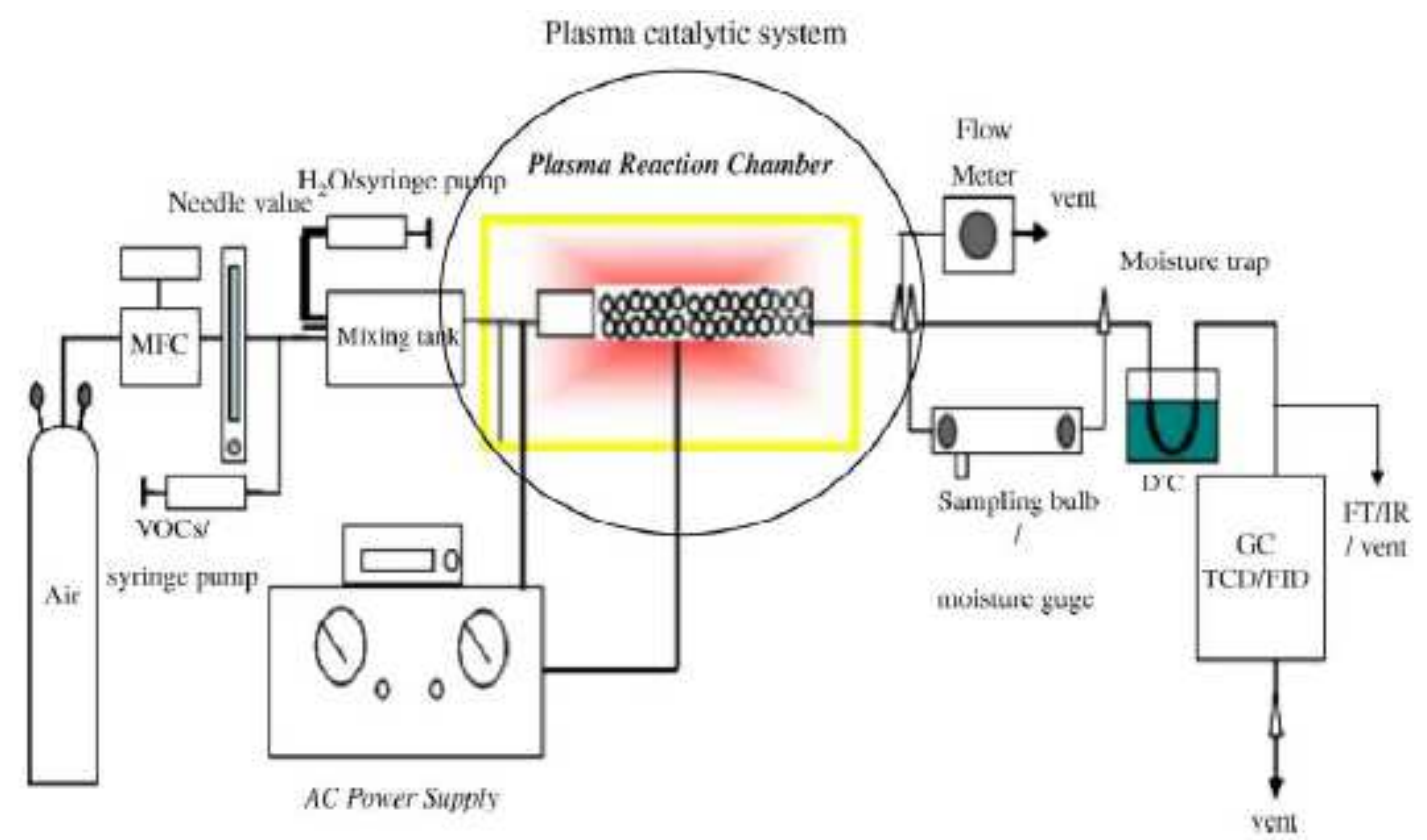

Figure 13 Schematic representation of discharge plasma reactor apparatus.

(1) Entrained powder feeder, (2) plasma gun, (3) cylindrical reactor (4) cooling chamber (5) powder collector, (6) scrubber and (7) bunsen burner. 


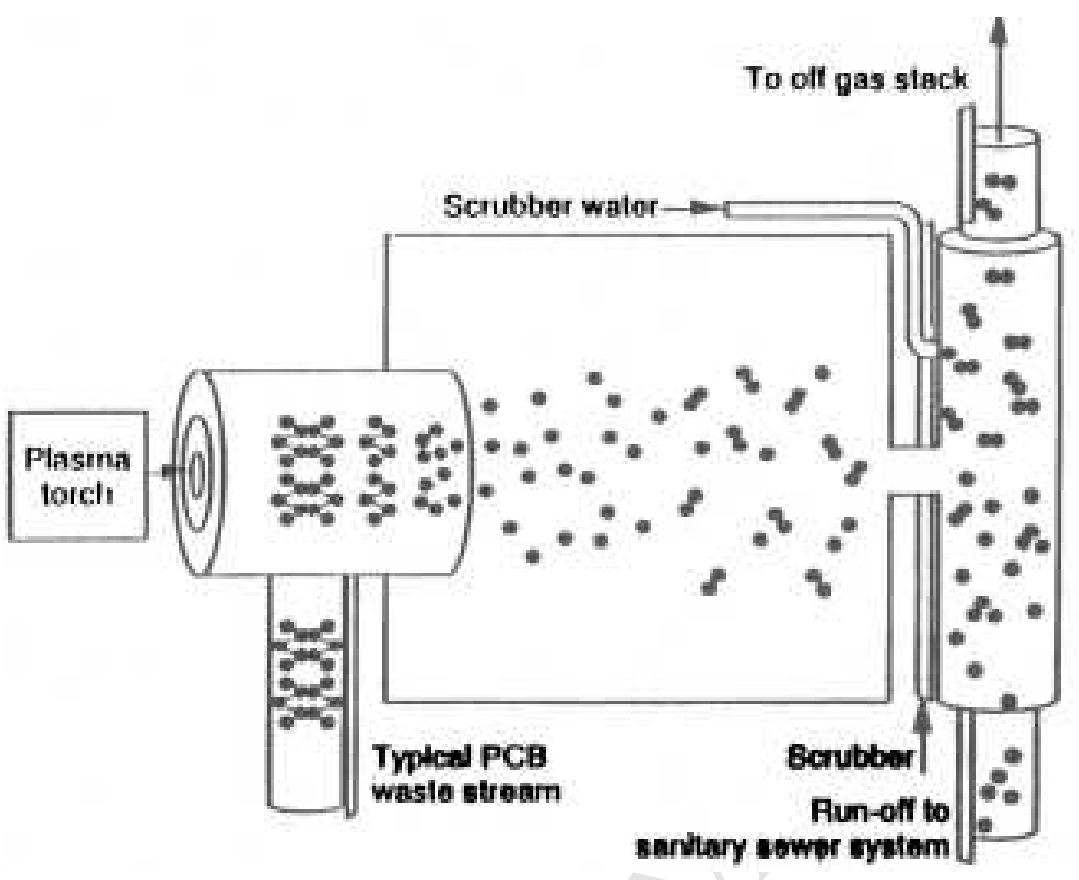

Fig. 14 Schematic diagram of pyrolysis unit for waste treatment.

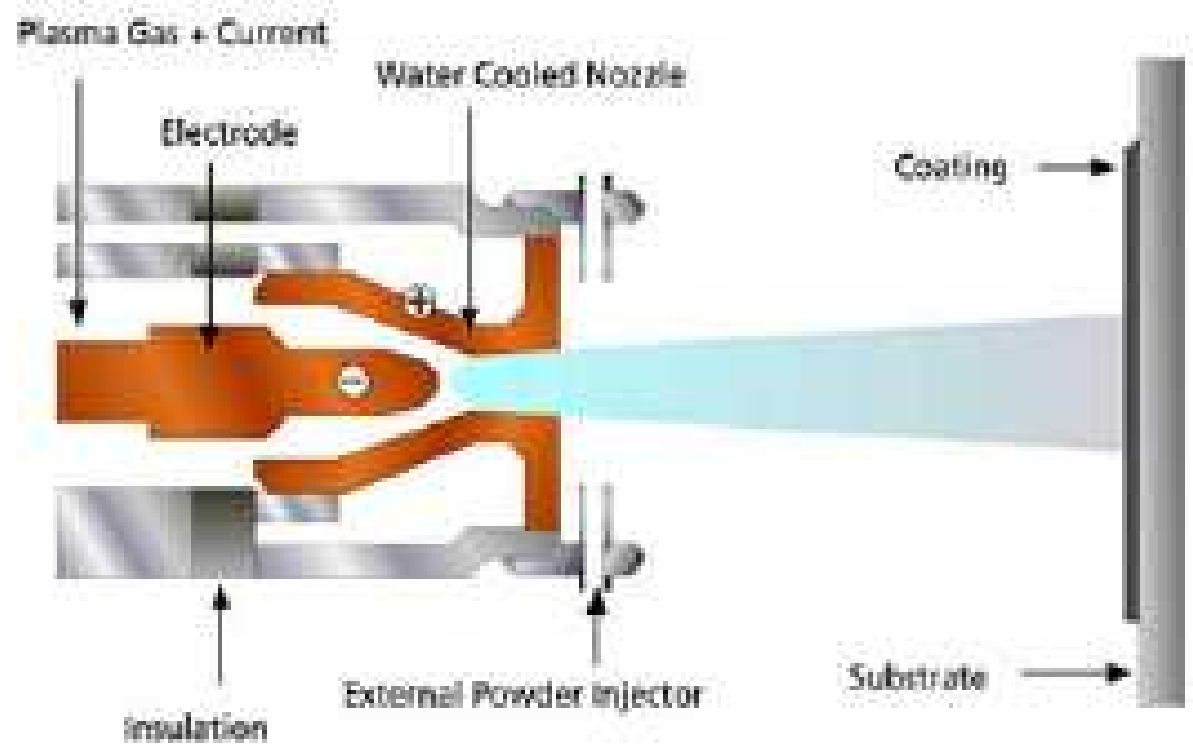

Fig 15 A schematic diagram of thermal plasma coating. 


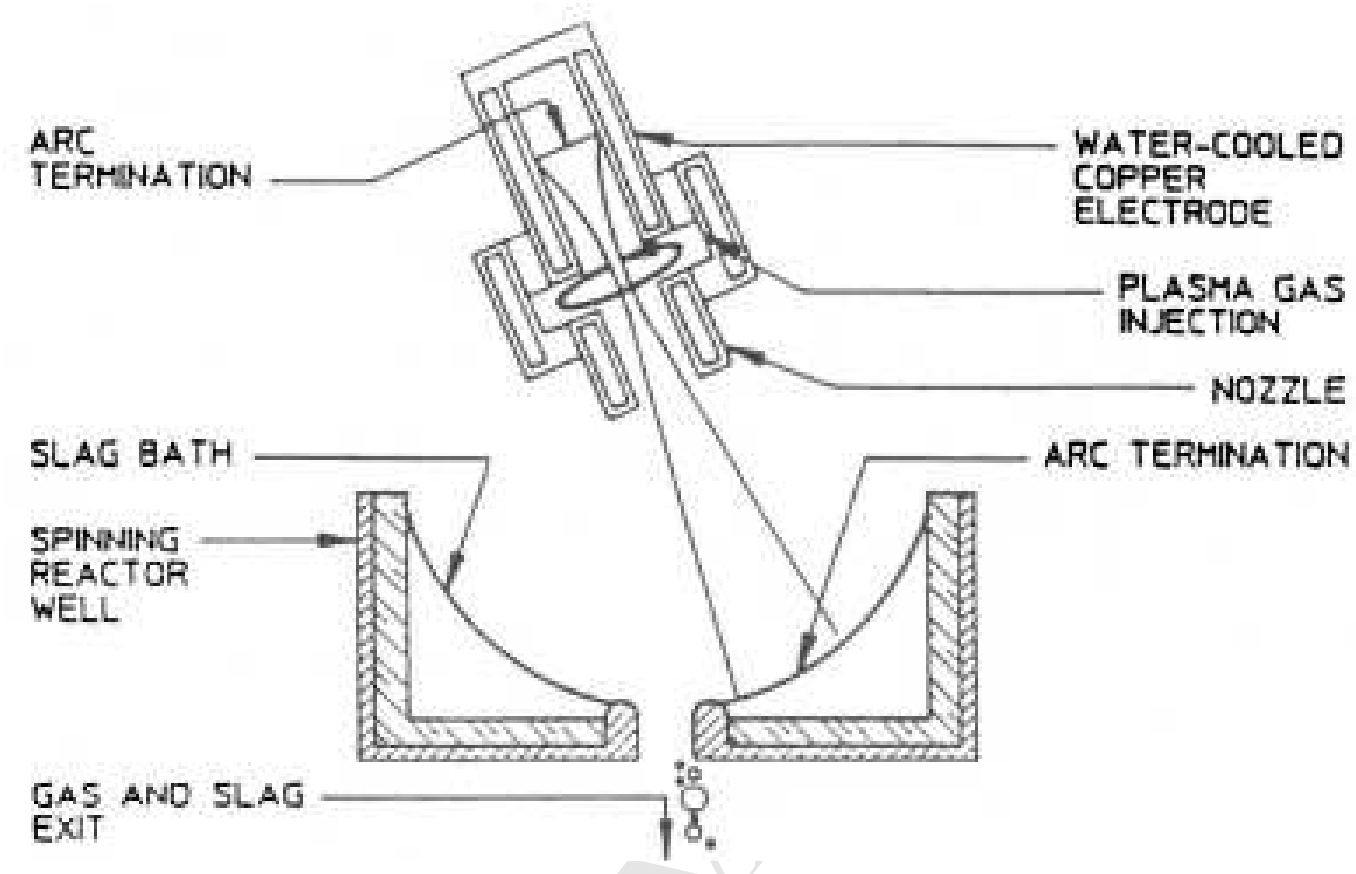

Fig. 16. Plasma technique for slag metallurgy. 


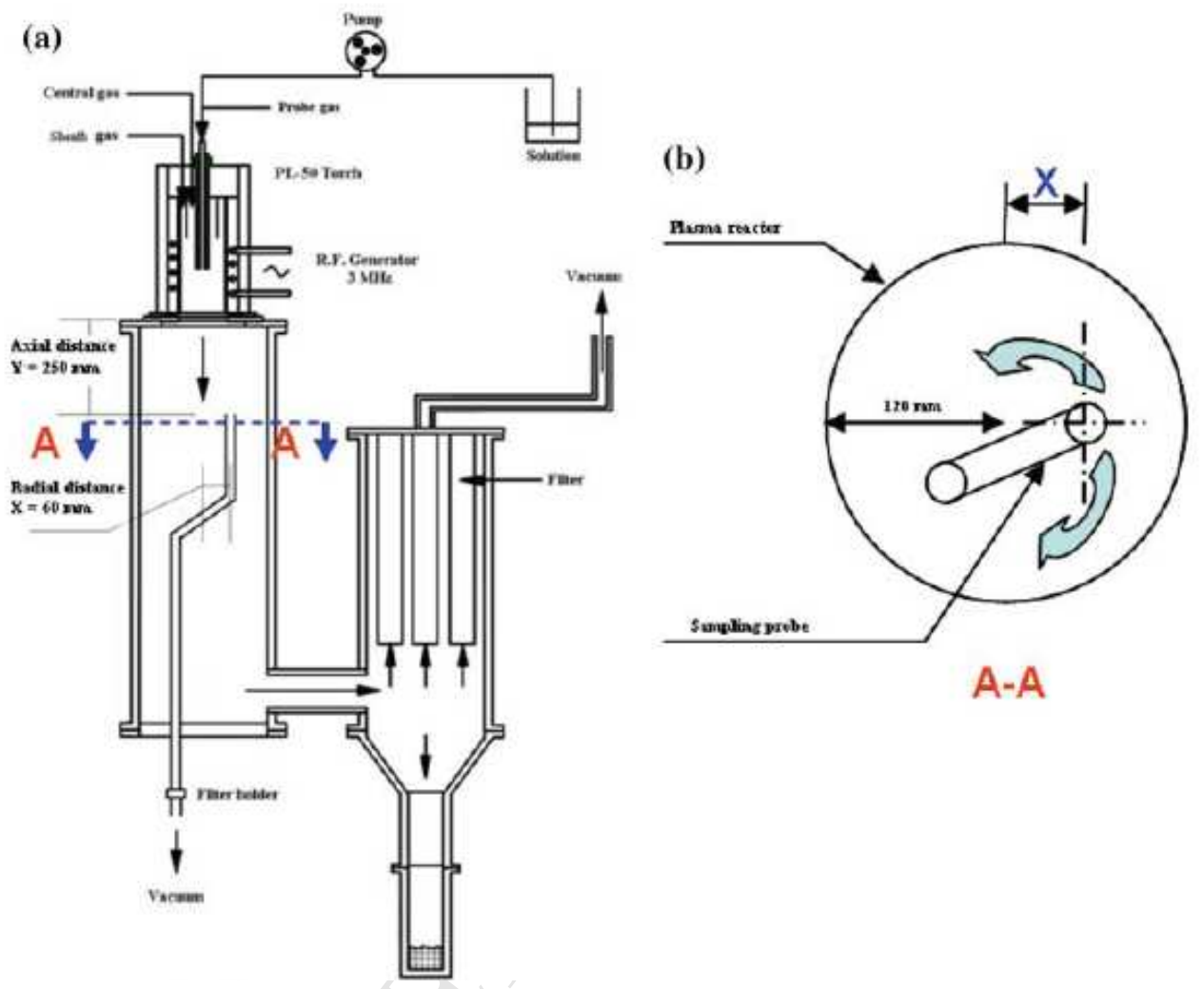

Figure 17 (a) RF plasma installation for RF-ICTP synthesis process.

(b) Cross section of RF plasma nano-powder. 


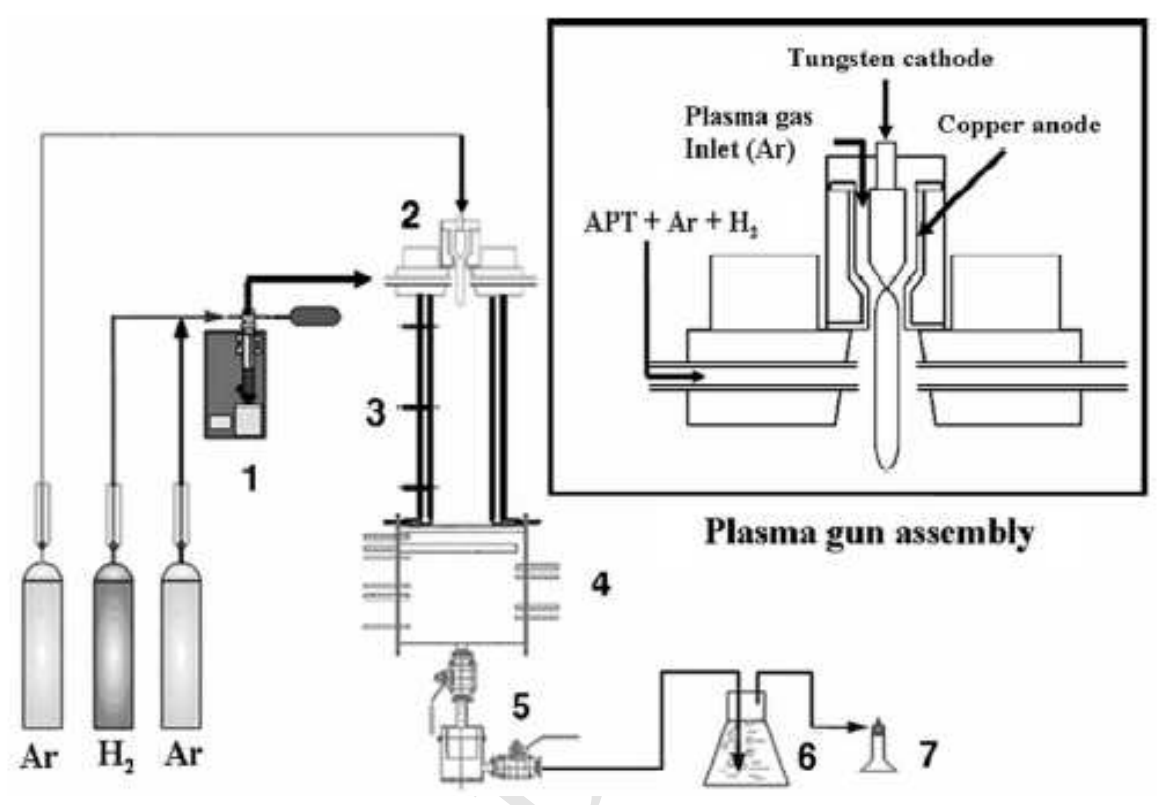

Fig. 18 Schematic diagram of plasma gun assembly for nano particle fabrication. 

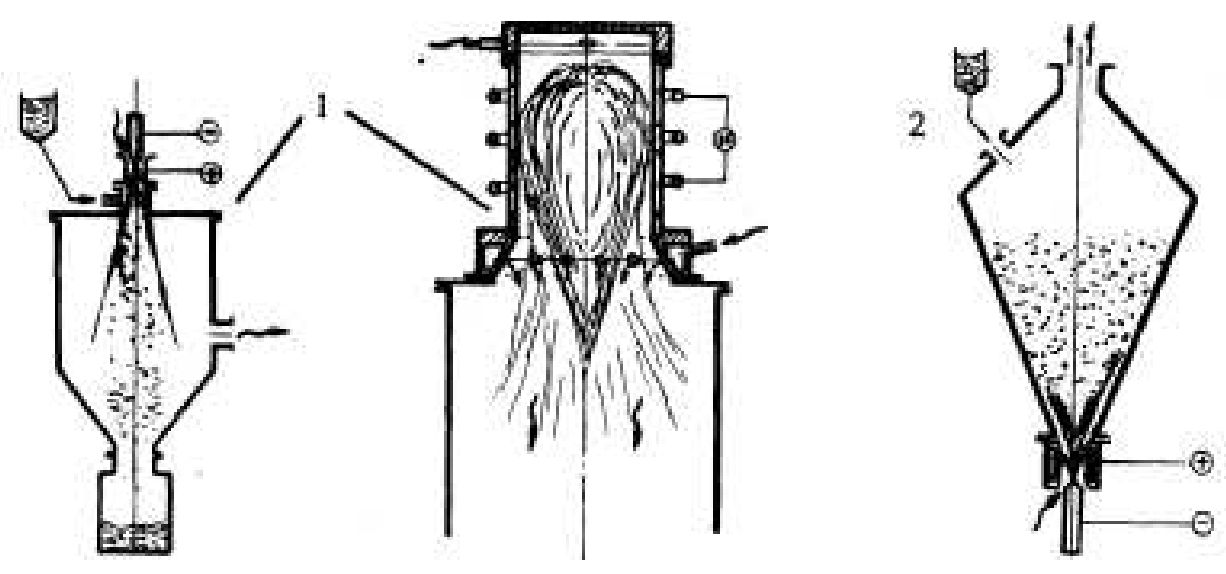

Fig. 19 Schematic diagram of plasma centrifugal furnace for metallurgical application. 
Highlights of the review article

- Review the technology until the present status

- Various types of technologies for the implication of this process

- Present and future scope in thermal plasma technology

- Implication of technology from industrial to commercialization way 